\title{
Membrane Lipid Modulations Remove Divalent Open Channel Block from TRP-Like and NMDA Channels
}

\author{
Moshe Parnas, ${ }^{1}$ Ben Katz, ${ }^{1}$ Shaya Lev, ${ }^{1}$ Vered Tzarfaty, ${ }^{1}$ Daniela Dadon, ${ }^{1}$ Ariela Gordon-Shaag,,${ }^{1,3}$ Henry Metzner, ${ }^{2}$ \\ Rami Yaka, ${ }^{2}$ and Baruch Minke ${ }^{1}$ \\ ${ }^{1}$ Department of Physiology and the Kühne Minerva Center for Studies of Visual Transduction, ${ }^{2}$ Department of Pharmacology, Faculty of Medicine of The \\ Hebrew University, and ${ }^{3}$ Hadassah Academic College, Jerusalem 91120, Israel
}

\begin{abstract}
Open channel block is a process in which ions bound to the inside of a channel pore block the flow of ions through that channel. Repulsion of the blocking ions by depolarization is a known mechanism of open channel block removal. For the NMDA channel, this mechanism is necessary for channel activation and is involved in neuronal plasticity. Several types of transient receptor potential (TRP) channels, including the Drosophila TRP and TRP-like (TRPL) channels, also exhibit open channel block. Therefore, removal of open channel block is necessary for the production of the physiological response to light. Because there is no membrane depolarization before the light response develops, it is not clear how the open channel block is removed, an essential step for the production of a robust light response under physiological conditions. Here we present a novel mechanism to alleviate open channel block in the absence of depolarization by membrane lipid modulations. The results of this study show open channel block removal by membrane lipid modulations in both TRPL and NMDA channels of the photoreceptor cells and CA1 hippocampal neurons, respectively. Removal of open channel block is characterized by an increase in the passage-rate of the blocking cations through the channel pore. We propose that the profound effect of membrane lipid modulations on open channel block alleviation, allows the productions of a robust current in response to light in the absence of depolarization.
\end{abstract}

Key words: TRP channels; Drosophila; photoreceptors; open channel block; NMDA channel; phospholipase C

\section{Introduction}

Open channel block (OCB) is a process in which ions have access to intrachannel binding sites inside the pore of an ion channel and block the flow of ions through that channel. The known mechanism of OCB removal is repulsion of the blocking ion by depolarization. For cyclic nucleotide gated channels, divalent OCB greatly improves the signal-to-noise ratio (Kaupp and Seifert, 2002). For the NMDA channel, OCB by $\mathrm{Mg}^{2+}$ and its removal by depolarization (Mayer et al., 1984) are crucial for the function of this channel as a coincident detector in the brain

Received Sept. 8, 2008; revised Jan. 11, 2009; accepted Jan. 13, 2009.

This work was supported by grants from the National Institutes of Health (EY 03529), the Israel Science Foundation, the German-Israeli Foundation, the Israel-Korea scientific cooperation program, the Moscona Foundation, and the Minerva Foundation. We thank Drs. Tamas Balla for the eGFP-tagged PH domain vector, Neil Nathanson for the DM1 vector, Neil S. Millar for the TRPL vector, and Vivian Teichberg for the NR1 and NR2B vectors. We also thank Drs. Françios Payre and Armin Huber for the antibodies against Dmoesin and PLC, respectively, Drs. Bertil Hille for a valuable discussion on ion permeation, and Hanna Parnas, Johannes Oberwinkler, Boaz Cook, and Jeremy Nathans for very useful comments and critical reading of this manuscript. M.P. contributed to all of the electrophysiological measurements and single-channel analysis in $\$ 2$ cells, model construction and simulations, interpretation of the data, and drafting and writing this manuscript. B.K. contributed to electrophysiological measurements in Drosophila TRPL channels. D.D. contributed to electrophysiological measurements in Drosophila TRP channels. S.L. contributed to confocal imaging, some of the electrophysiological recordings in S2 cells, and cloning. V.T. contributed to the biochemistry and cloning. A.G.-S. contributed to the cloning. H.M. and R.Y. contributed to the electrophysiological measurements in brain slices. B.M. contributed to interpretation of the data, and drafting and writing this manuscript.

Correspondence should be addressed to Baruch Minke, Department of Physiology, Faculty of Medicine, The Hebrew University, P. 0. Box 12272, Jerusalem 91120, Israel. E-mail: minke@md.huji.ac.il.

DOI:10.1523/JNEUROSCI.4280-08.2009

Copyright $\odot 2009$ Society for Neuroscience $\quad$ 0270-6474/09/292371-13\$15.00/0
(Nowak et al., 1984). Accordingly, the ligand-gated NMDA channel cannot open by application of its ligands in resting membrane potential due to $\mathrm{OCB}$, and depolarization is required to remove this block (Kandel, 2000). The Drosophila light activated channels TRPL and TRP also undergo divalent OCB [transient receptor potential-like (TRPL) (Parnas et al., 2007), TRP (Hardie and Mojet, 1995)]. Because there is no membrane depolarization to remove the divalent OCB before activation of the TRPL and TRP channels, it is not clear how the robust $(>4 \mathrm{nA})$ light induced current develops at light onset. This fundamental difficulty in understanding Drosophila phototransduction has been ignored but needs to be resolved.

The TRP superfamily is conserved throughout evolution and plays important roles in signal transduction in many cells types (Minke and Cook, 2002; Clapham, 2003; Jordt et al., 2003; Voets et al., 2004; Montell, 2005; Dhaka et al., 2006; Hardie, 2007). Experimental evidence has suggested that several members of the TRP family [e.g., TRPC2 (Lucas et al., 2003), TRPC6 (Spassova et al., 2006), TRPV3 (Hu et al., 2006), TRPM6 (Topala et al., 2007), and TRPM7 (Nadler et al., 2001)] undergo OCB. However, the physiological mechanism underlying the alleviation of OCB in TRP channels is still unknown. Lipids were found to activate or modulate TRP and NMDA channels. Accordingly, diacylglycerol (DAG) activates TRPC2 (Lucas et al., 2003), TRPC3 (Hofmann et al., 1999), TRPC6 (Hofmann et al., 1999), and TRPC7 (Okada et al., 1999). Polyunsaturated fatty acids (PUFA) activate the Drosophila TRP and TRPL (Chyb et al., 1999), the mammalian 
TRPV3 (Hu et al., 2006), and the NMDA channels (Miller et al., 1992). However, the underlying mechanism of the lipids action is not clear.

In the present study, we show that the application of lipids removes divalent OCB without depolarization from both TRPL and NMDA channels, by facilitating the passage rate of the blocking cations in the channels' pore. We suggest that the effect of lipids is indirect and operates by modulating interactions between membrane lipids and the channels. We propose that the profound effect of membrane lipid modulations on open channel block alleviation, allows the productions of a robust current in response to light in the absence of depolarization.

\section{Materials and Methods \\ Drosophila}

Fly stocks. White-eyed Drosophila of the following strains were used: $\operatorname{tr} p^{P 343}$ and norp $A^{p 24} ;$;rp ${ }^{p 343}$. Flies were raised at $24^{\circ} \mathrm{C}$ in a $12 \mathrm{~h}$ light/dark cycle. For the experiments of Figure $2 C$, flies were raised in darkness to prevent light induced degeneration of the norp $A^{p 24} ;$;rp $p^{p 343}$ eyes.

Light stimulation. A xenon high-pressure lamp (PTI, LPS 220, operating at 50W, Lawrenceville, NJ) was used and the light stimuli were delivered to the ommatidia by means of epi-illumination via an objective lens (in situ). The intensity of the orange light (Schott OG 590 edge filter) at the specimen, with no intervening neutral density filters, was $13 \mathrm{~mW} /$ $\mathrm{cm}^{2}$ and it was attenuated by neutral density filters in log scale.

Cell culture. Schneider S2 cells were grown in $25 \mathrm{~cm}^{2}$ flasks, at $25^{\circ} \mathrm{C}$ in Schneider medium (Beit Haemek Biological Industries) supplemented with $10 \%$ fetal bovine serum and $1 \%$ pen-strep. TRPL-eGFP (TRPL accession number NM_165694) channels were stably expressed and NMDA channels (accession numbers: NR1, NM_017010; and NR2, NM_012574), were transiently expressed using Escort IV (Sigma).

Electrophysiology. For S2 cells, cells were seeded on polylysine coated plates at a confluence of $25 \%, 24-72 \mathrm{~h}$ before the experiment. Twentyfour hours before the experiment, $500 \mu \mathrm{M} \mathrm{CuSO}_{4}$ was added to the medium to induce expression of the channels. For Drosophila ommatidia, dissociated Drosophila ommatidia were prepared from newly emerged flies ( $<1 \mathrm{~h}$ after eclosion) and whole-cell, patch-clamp recordings were performed as described previously (Peretz et al., 1994). Whole-cell and single-channel currents are recorded at room temperature using borosilicate patch pipettes of 5-8 $\mathrm{M} \Omega$ and an Axopatch 1D (Molecular Devices) voltage-clamp amplifier. For single-channel recordings, pipettes were coated with Dow Corning Sylgard. For S2 cells, voltage-clamp pulses were generated and data captured using a Digidata 1322A interfaced to a computer running the pClamp 9.2 software (Axon Instruments). For Drosophila ommatidia, Digidata 1200 and pClamp 8.0 software (Molecular Devices) were used. Currents were filtered using the 8-pole low pass Bessel filter of the patch-clamp amplifier at $10 \mathrm{kHz}$ and sampled at $50 \mathrm{kHz}$ (single-channel recordings) or filtered at $5 \mathrm{kHz}$ and sampled at $20 \mathrm{kHz}$ (whole-cell recordings). To measure current-voltage $(I-V)$ curves with minimal distortions, only cells with low $(<10 \mathrm{M} \Omega)$ series resistance were used and the series resistance was compensated by $\sim 80 \%$.

Western blot analysis. Two flies' heads were used for each lane of the Western blots. Proteins were extracted with $1 \times$ SDS-PAGE buffer $(2 \%$ SDS, 100 mм DTT, 10 glycerol in 65 mm Tris-HCl, pH 6.8) and subjected to SDS-PAGE using $8 \%$ polyacrylamide gels (Midget System, GE Healthcare). Protein levels were detected using anti-TRP (monoclonal, MAb83F6, a gift from S. Benzer, California Institute of Technology, Pasadena, CA), anti-PLC (polyclonal, a gift from A. Huber, University of Hohenheim, Stuttgart, Germany) and anti-Dmoesin (polyclonal, a gift from F. Payre, Centre National de la Recherche Scientifique, Université Paul Sabatier, Toulouse, France) antibodies.

Confocal imaging. For measurements of eGFP-tagged PH domain, optical sections of S2 cells were visualized using the Fluoview confocal microscope (model 300 IX70; Olympus) using Olympus UplanF1 60×/ 0.9 water objective. Optical sections were recorded from the middle of the cell.

Solutions. For S2 cells, standard extracellular solution contained in
mM: $150 \mathrm{NaCl}, 5 \mathrm{KCl}, 4 \mathrm{MgCl}_{2}, 10 \mathrm{TES}, 25$ proline, 5 alanine, and 0.5 EGTA. Standard intracellular solution contained in mM: $130 \mathrm{CsCl}, 10$ TES, $2 \mathrm{MgCl}_{2}, 4 \mathrm{Mg}$-ATP, $0.4 \mathrm{Na}-\mathrm{GTP}$ and 15 TEA. For Drosophila ommatidia, the extracellular solution contained the following (in $\mathrm{mm}$ ): $120 \mathrm{NaCl}, 5 \mathrm{KCl}, 4 \mathrm{MgSO}_{4}, 10 \mathrm{TES}, 25$ proline, 5 alanine $\left(1.5 \mathrm{~mm} \mathrm{Ca}^{2+}\right.$ was added when light stimulation was used, to allow PLC activity). The intracellular solution, which blocked $\mathrm{K}^{+}$channels, contained in mM: 120 $\mathrm{CsCl}, 10 \mathrm{TES}, 2 \mathrm{MgSO}_{4}, 4 \mathrm{Mg}$-ATP, $0.4 \mathrm{Na}-\mathrm{GTP}, 1 \beta$-NAD and 15 TEA. All solutions were titrated to $\mathrm{pH} 7.15$. Cells were perfused via BPS-8 valve control system (Scientific Instruments) at a rate of $\sim 30$ chambers per min. Chemicals were applied via the perfusion system.

Data analyses. Data were analyzed and plotted using pClamp 9.2 software (Molecular Devices) and Sigma Plot 8.02 software (Systat software). Kinetic analysis, single-channel event identification and burst analysis were performed as previously described (Parnas et al., 2007). For event histograms, only events longer than twice $T_{\mathrm{r}}$ were used (Colquhoun and Sigworth, 1995). The single-channel current amplitude was calculated relative to the closed state base line (as implemented in the pClamp 9.2 softwere). Accordingly an automatic correction for baseline drifts is given and the average current of the closed state remains zero. Therefore, the events histograms present only the channel openings which are already corrected for baseline drifts.

Statistical analysis. For statistical analysis, student's $t$ test was used. All error bars are SEM.

\section{Rat brain slices: Electrophysiology}

For whole-cell recordings from hippocampal brain slices, we used the experimental procedure as described previously (Crépel et al., 1997). Briefly, Sabra male rats (Harlan), 28-32 d old, were anesthetized and killed. The brain was rapidly dissected, and coronal hippocampal slices $(350 \mu \mathrm{m})$ were cut on a vibratome VT-1000 (Leica) in ice-cold artificial CSF (aCSF), containing the following (in $\mathrm{mm}$ ): $126 \mathrm{NaCl}, 1.6 \mathrm{KCl}, 2.4$ $\mathrm{CaCl}_{2}, 1.2 \mathrm{NaH}_{2} \mathrm{PO}_{4}, 1.2 \mathrm{MgCl}_{2}, 18 \mathrm{NaHCO}_{3}$ and 11 glucose, saturated with $95 \% \mathrm{O}_{2}$ and $5 \% \mathrm{CO}_{2}$. Slices were allowed to recover for at least 1-2 $\mathrm{h}$ in aCSF at $32^{\circ} \mathrm{C}$ and were then transferred to a chamber with continuous flow $(2.5 \mathrm{ml} / \mathrm{min}$ ) of aCSF that contained $10 \mu \mathrm{M}$ CNQX (Sigma) and $100 \mu \mathrm{M}$ picrotoxin (Sigma) to block AMPAR EPSCs and GABA RIP- $^{-}$ SCSs, respectively. Cells were visualized using an upright microscope with infrared illumination. Whole-cell voltage-clamp recordings were performed using Multiclamp 700B amplifier (Molecular Devices). Electrodes pulled from glass capillaries (2-4 M $\Omega$ resistance) were filled with a solution ( $\mathrm{pH} 7.2-7.4)$ containing the following (in $\mathrm{mm}$ ): 117 $\mathrm{CsCH}_{3} \mathrm{SO}_{3}$, 20 HEPES, 0.4 EGTA, $2.8 \mathrm{NaCl}, 5 \mathrm{~N}\left(\mathrm{CH}_{2} \mathrm{CH}_{3}\right)_{4} \mathrm{Cl}, 2.5 \mathrm{Mg}$ ATP, $0.25 \mathrm{Mg}$-GTP. A bipolar stimulating electrode was placed in the Schaffer collateral/commissural afferents within the CA1 region and recording were made from pyramidal hippocampal neurons in the CA1. Afferents were stimulated at $0.1 \mathrm{~Hz}$ to evoke EPSCs. EPSCs were filtered at $2 \mathrm{kHz}$, digitized at $5-10 \mathrm{kHz}$ and recorded using Igor Pro software (Wavemetrics). I- $V$ curves of NMDAR EPSCs were generated by recordings at holding potentials that ranged from -70 to $+40 \mathrm{mV}$, at $10 \mathrm{mV}$ increments. Linoleic acid was applied through the patch pipette by means of diffusional exchange.

\section{Results}

\section{Linoleic acid removes divalent OCB from heterologously expressed and native TRPL channels from the photoreceptor} cell

Under physiological conditions at steady state, the divalent OCB of both TRPL (Fig. $1 B$ ) and TRP (supplemental Fig. S2A, available at www.jneurosci.org as supplemental material) channels is manifested in the current-voltage relationships ( $I-V$ curves), when the channels are activated either by light (pink $I-V$ curves) or by low concentration of linoleic acid (LA) (blue $I-V$ curves). These $I-V$ curves revealed strong outward rectification implying that these channels are nearly closed in the physiological voltage range of -60 to $10 \mathrm{mV}$. Robust openings were only observed at a nonphysiological positive voltage range (Raghu et al., 2000). In contrast to the minor currents observed in the $I-V$ curves at -60 


\section{With divalent}
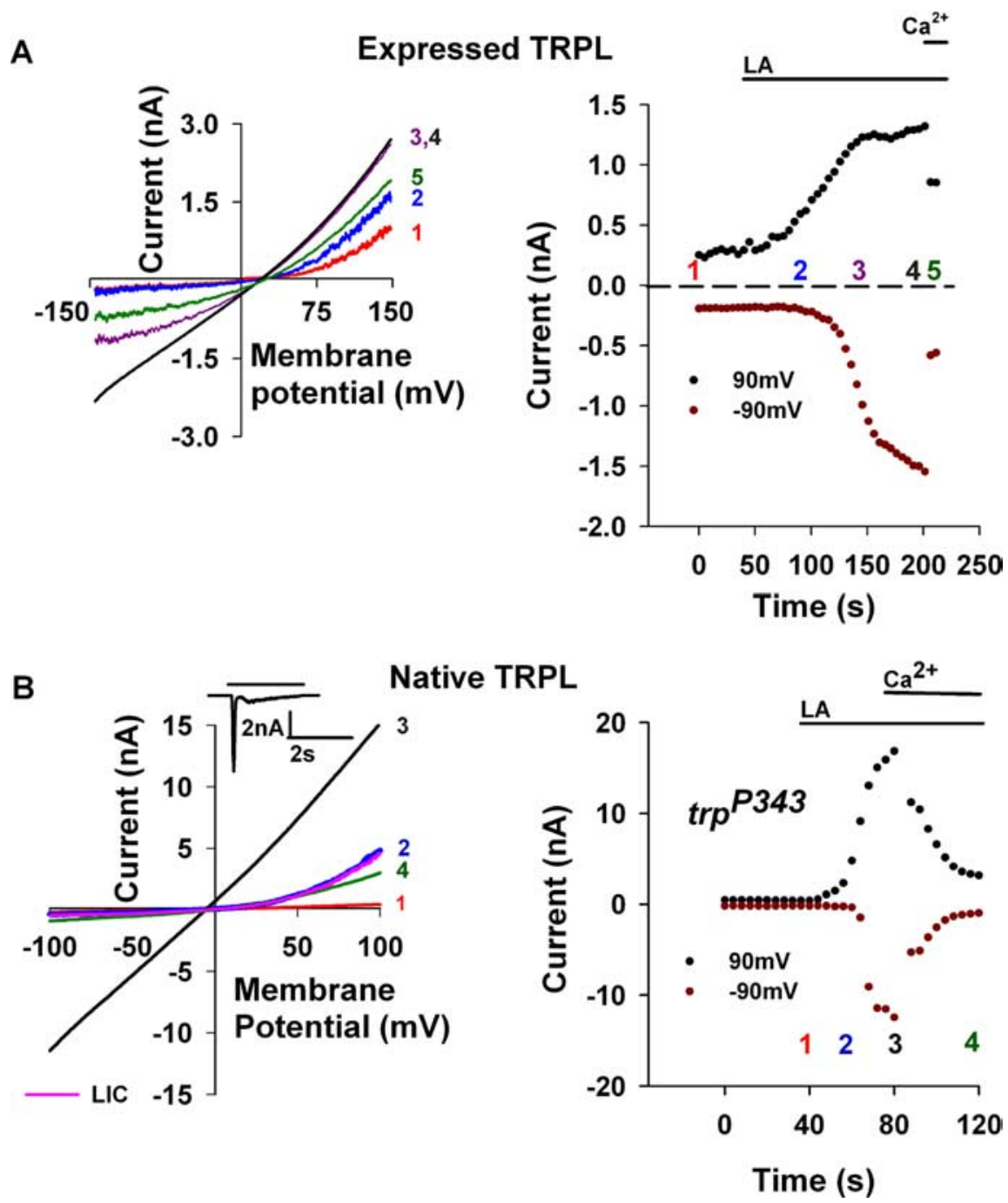

Figure 1. Linoleic acid removed OCB from TRPL channels. $A$, Left, Representative $I-V$ curves measured from $S 2$ cells by whole-cell patch-clamp recordings using voltage ramps from -150 to $150 \mathrm{mV}$ in $1 \mathrm{~s}$. The typical outward rectification of the TRPL channels (red curve 1) was modified to a linear I-V curve after application of $40 \mu \mathrm{m}$ LA (black curve 4). The effect at positive membrane potentials preceded that of negative membrane potentials (curves 2 and 3 , blue and purple respectively, see also $A$, right). Application of $5 \mathrm{~mm} \mathrm{Ca}^{2+}$ restored the outward rectifying I-V curve (green curve 5). Right, The current values at $90 \mathrm{mV}$ (black dots) and $-90 \mathrm{mV}$ (dark red dots) are presented as a function of time. The numbers correspond to the curves presented in $\boldsymbol{A}$, left ( $n=15)$. $\boldsymbol{B}$, Left, Representative I-V curves measured as in $\boldsymbol{A}$ from mutant Drosophila ommatidia that express only TRPL channels (trp ${ }^{P 343}$ ). In darkness the TRPL channels were closed (red curve 1). After application of $60 \mu \mathrm{m} L A$, a linear $I-V$ curve was obtained (black curve 3). The effect of $L A$ at positive membrane potentials preceded the effect at negative membrane potentials in a similar manner to expressed channels (blue curve 2). Application of $10 \mathrm{~mm} \mathrm{Ca}{ }^{2+}$ blocked the TRPL channel (green curve 4, left), ruling out the possibility that the linear $I-V$ curve was due to leak current. Right, The effect of $L A$ on the current is presented as a function of time at $90 \mathrm{mV}$ (black dots) and $-90 \mathrm{mV}$ (dark red dots). The numbers correspond to the curves presented in $\boldsymbol{B}$, left $(n=5)$. The $I-V$ curve of the LIC is presented in pink (the maximal light intensity was attenuated by $2 \log$ units). The inset shows the LIC of the trp ${ }^{P 343}$ mutant in response to the above light intensity.

$\mathrm{mV}$, whole-cell recordings from isolated ommatidia of the $\operatorname{tr} p^{P 343}$ (Fig. $1 B$, inset) and $\operatorname{trpl}^{302}$ null mutants (supplemental Fig. S2A, inset, available at www.jneurosci.org as supplemental material, which express only the TRPL and TRP channels, respectively) (Scott et al., 1997) revealed robust transient light induced current (LIC, $>4 \mathrm{nA}$ ) at the onset of the response to a light pulse at -60 $\mathrm{mV}$ membrane potential (Fig. $1 B$, inset; supplemental Fig. S2A, inset, available at www.jneurosci.org as supplemental material). OCB is a very fast and efficient process (Hille, 1992) and every activated channel is expected to be immediately blocked on open- ing. Because there is no membrane depolarization before TRPL and TRP channels open to remove the divalent OCB observed in the $I-V$ curves, it is not clear how these robust LICs develop in response to light (Fig. $1 B$; supplemental Fig. S2A, insets, available at www.jneurosci.org as supplemental material). The apparent contradiction between the results of the $I-V$ curve and the LIC (Fig. 1; supplemental Fig. S2A, available at www.jneurosci. org as supplemental material), presents a fundamental difficulty in understanding Drosophila phototransduction, which needs to be resolved.

A possible explanation for this contradiction is that light and LA have a dual role: (1) to activate the channels and (2) to remove OCB. A convenient preparation to isolate channel activation from removal of OCB is heterologously expressed TRPL channels in Schneider 2 (S2) cells.

In Drosophila photoreceptor cells, the TRPL and TRP channels are closed in the dark and cannot be activated by depolarization (Fig. $1 B$, red curve 1 ). In contrast, TRPL channels heterologously expressed in S2 cells are constitutively active (Fig. $1 A$, red curve 1 ) but otherwise have the same properties as the native channels of the photoreceptor cell (Hardie et al., 1997). Importantly, the constitutively active TRPL channels still reveal OCB, as manifested by a strong outward rectification (Fig. $1 A$, red) and very little singlechannel activity (see Fig. 5A, left) at negative membrane potentials (Parnas et al., 2007). This property of the expressed TRPL channels enables us to isolate OCB removal by lipids from channel activation. Whereas functional TRPL channels can be easily expressed, functional expression of the TRP channel could not be obtained (Minke and Parnas, 2006). For this reason, the study of the mechanism of OCB removal without depolarization was performed on heterologously expressed TRPL channels and the main findings were confirmed in the native system of the photoreceptor cells.

OCB is characterized by an outwardly rectifying $I-V$ curve. Removal of this block results in linearization of the $I-V$ curve. Therefore, we first examined whether application of LA results in linearization of the TRPL $I-V$ curve in the presence of divalent cations. To this end, we measured $I-V$ curves every $5 \mathrm{~s}$ from TRPL channels expressed in S2 cells. Before application of LA, outward rectification of the constitutively active TRPL channels was observed with $4 \mathrm{mM} \mathrm{Mg}^{2+}$ (Fig. 1 A left, red curve 1 ) indicating OCB by $\mathrm{Mg}^{2+}$. Application of LA $(40 \mu \mathrm{M})$ gradually caused linearization of the $I-V$ curve (Fig. $1 A$, black curve 4 ). Because LA could not be washed out, we applied a high $(5 \mathrm{~mm})$ concentration of $\mathrm{Ca}^{2+}$, which restored the outwardly rectifying $I-V$ curve by shift- 
ing the equilibrium of the divalent cations-binding sites at the channel pore toward the bound states (Hille, 1992) (Fig. $1 \mathrm{~A}$ left, green curve 5). (For statistical analysis, see supplemental Fig. $\mathrm{S} 1 A$, available at www.jneurosci.org as supplemental material.) To confirm that the effects seen in Figure $1 A$ are specific, control experiments were conducted with the following results. (1) Application of up to $100 \mu \mathrm{M}$ LA did not show any effect on S2 cells, in untransfected S2 cells (supplemental Fig. S1A, available at www.jneurosci.org as supplemental material). (2) In the absence of LA, no increase of channel openings was observed (supplemental Fig. S1B, available at www.jneurosci.org as supplemental material). (3) Application of the water soluble isoform of LA (Na-LA), which does not form micelles in aqueous solution, yielded the same results as LA (data not shown). In addition, application of other lipids, such as oleic acid and stearoylarachidonylglycerol, an analog of the PLC product DAG, revealed effects similar to those produced by LA (data not shown).

To examine whether the application of LA also results in linearization of the $I-V$ curve of the native TRPL and TRP channels in Drosophila photoreceptor cells, we performed whole-cell recordings from isolated ommatidia of the $\operatorname{trp} p^{P 343}$ and $\operatorname{trpl} l^{302}$ null mutants, which express only the TRPL and TRP channels, respectively (Scott et al., 1997). We performed the same protocol as that in Figure $1 A$ and obtained similar results from the native (Fig. $1 B$ ) and the heterologously expressed TRPL channels (Fig. 1A). For the native TRP channels, a full linearization of the $I-V$ curve was not observed, but the outwardly rectifying $I-V$ curve was changed into a dually rectifying curve, similar to that observed under divalent free conditions (supplemental Fig. S2A, available at www.jneurosci.org as supplemental material) (Hardie and Minke, 1994).

The results of Figure 1 are consistent with the notion that in active TRPL and TRP channels, both application of LA at resting membrane potential or depolarization remove OCB by divalent cations (Parnas et al., 2007).

\section{The effect of LA is not mediated via activation of PLC}

It was previously suggested that the effects of LA on the TRPL channel is relayed via PLC (Estacion et al., 2001; Minke and Parnas, 2006). To examine this notion, we tested the effect of LA on PLC activity in S2 cells. It is well known that activation of PLC results in the hydrolysis of phosphatidylinositol 4,5-bisphosphate $\left(\mathrm{PIP}_{2}\right)$ into DAG and inositol trisphosphate $\left(\mathrm{IP}_{3}\right)$ (Berridge and Irvine, 1989). To measure PLC activity in situ, we coexpressed in S2 cells the Drosophila muscarinic receptor DM1 (which activates PLC via a Gq-protein) (Hardie et al., 1997) along with eGFPtagged pleckstrin homology $(\mathrm{PH})$ domain from PLC- $\delta 1$ (eGFP$\mathrm{PH}$, which binds to $\mathrm{PIP}_{2}$ and $\mathrm{IP}_{3}$ (Balla and Várnai, 2002; Suh et al., 2006). The latter was expressed to directly show PIP $_{2}$ hydrolysis indicating PLC activity, because of its high affinity binding to both $\mathrm{PIP}_{2}$ and $\mathrm{IP}_{3}$. When PLC is inactivated eGFP-PH is located at the plasma membrane bound to $\mathrm{PIP}_{2}$. On activation of PLC, eGFP-PH translocates from the plasma membrane to the cytosol because of the hydrolysis of $\mathrm{PIP}_{2}$ and the production of $\mathrm{IP}_{3}$ (Balla and Várnai, 2002; Suh et al., 2006).

In control conditions before application of LA, strong eGFP fluorescence was observed at the plasma membrane, indicating localization of $\mathrm{PIP}_{2}$ in the plasma membrane (Fig. $2 \mathrm{~A}$, control). Application of $50 \mu \mathrm{M} \mathrm{LA}$, which is sufficient to activate TRPL channels (Fig. $1 A$ ), did not change eGFP-PH distribution (Fig. $2 A$, LA), indicating that PLC was not activated. Application of carbachol $(\mathrm{CCH})$, an activator of DM1, which was used as a positive control, elicited a robust translocation of eGFP-PH to the cytosol, indicating activation of PLC (Fig. 2A, CCH). The translocation of eGFP-PH was reversible after washing the $\mathrm{CCH}$ from the cells (Fig. $2 A$, wash, see also $2 A$, right). Together, Figures $1 A$ and $2 A$ show that LA activates the TRPL channels without activation of PLC as monitored by hydrolysis of $\mathrm{PIP}_{2}$.

To examine whether the above conclusion is also valid for the native TRPL channels in the photoreceptor cells, we constructed the double mutant norp $A^{P 24} ; \operatorname{trp}^{P 343}$ (Fig. $2 B$ ) and repeated the experiments described in Figure $1 B$. The norp $A^{P 24} ;$;rp $p^{P 343}$ double mutant lacks the TRP channels and virtually lacks the eye PLC (NORPA) (Bloomquist et al., 1988) (Fig. 2 B). Results very similar to those of Figure $1 B$ were obtained after the application of LA to the $\operatorname{norp} A^{P 24} ; \operatorname{trp}^{P 343}$ mutant (Fig. 2C), indicating that both TRPL activation by LA and removal of OCB by LA do not require PLC.

Together, the experiments described in Figure 2 ruled out the possibility that LA action is mediated via PLC and suggest a direct effect of LA on the channels in both experimental systems (Hardie et al., 2003).

\section{A reduction of OCB by activation of PLC in both expressed and native TRPL channels}

We next examined whether removal of OCB by exogenous application of LA is pertinent to alleviation of OCB under more physiological conditions. Although the effect of LA is not mediated through activation of PLC (Fig. 2), it has been well established that PLC activation hydrolyzes $\mathrm{PIP}_{2}$ and produces DAG and PUFAs (Leung et al., 2008). In addition, under physiological conditions PLC is necessary for TRPL activation (Cook et al., 2000). Because OCB removal is required for production of a robust TRPL and TRP-mediated current under physiological conditions, it was interesting to examine whether activation of PLC alleviates OCB in a manner similar to that of LA action in these channels. To monitor PLC activity we used the experimental tools described in Figure 2 and coexpressed TRPL channel together with the Drosophila muscarinic receptor DM1 and eGFP-PH in S2 cells (Balla and Várnai, 2002; Suh et al., 2006) (see also Fig. 2). Under control conditions, the plasma membrane is strongly marked by eGFP fluorescence due to binding of eGFP-PH to PIP $_{2}$ in the plasma membrane (Fig. $3 A$, control). On application of $\mathrm{CCH}$, eGFP-PH translocated to the cell body (Fig. $3 A, \mathrm{CCH})$. This translocation was reversible with the removal of $\mathrm{CCH}$ (Fig. $3 A$, wash; see also Fig. $2 A$, right). Thus, Figure $3 A$ demonstrates reversible activation of PLC by $\mathrm{CCH}$ as monitored by hydrolysis of $\mathrm{PIP}_{2}$. Application of $\mathrm{CCH}$ to $\mathrm{S} 2$ cells coexpressing DM1, TRPL and eGFP-PH caused a near linearization of the TRPL $I-V$ curve (Fig. 3B, left). When the DM1 receptor was not expressed, application of $\mathrm{CCH}$ did not induce any inward current (Fig. 3B, right) or translocation of eGFP-PH (data not shown). To quantify the effect of CCH on the TRPL outward rectification, we compared the current ratio $\left(I_{80 \mathrm{mV}} / I_{-80 \mathrm{mV}}\right)$ after application of $\mathrm{CCH}$ to the control. The current ratio was reduced from $5.26 \pm 0.74$ to $1.85 \pm 0.19(n=6)$, demonstrating a significant decrease in the outward rectification after activation of PLC. This result demonstrates that OCB of TRPL can be reduced by receptor-activation of PLC.

We next examined whether light stimulation, in addition to native channel activation, also removes OCB. In Drosophila photoreceptor cells, it is well known that light activates the TRPL and TRP channels via PLC (Devary et al., 1987; Bloomquist et al., 1988). Therefore, we examined whether light activation of PLC reduces the outward rectification of the native TRPL and TRP channels. To this end, we performed whole-cell recordings from isolated ommatidia of the $\operatorname{trp} p^{P 343}$ and $\operatorname{trpl}^{302}$ null mutants, which 
A

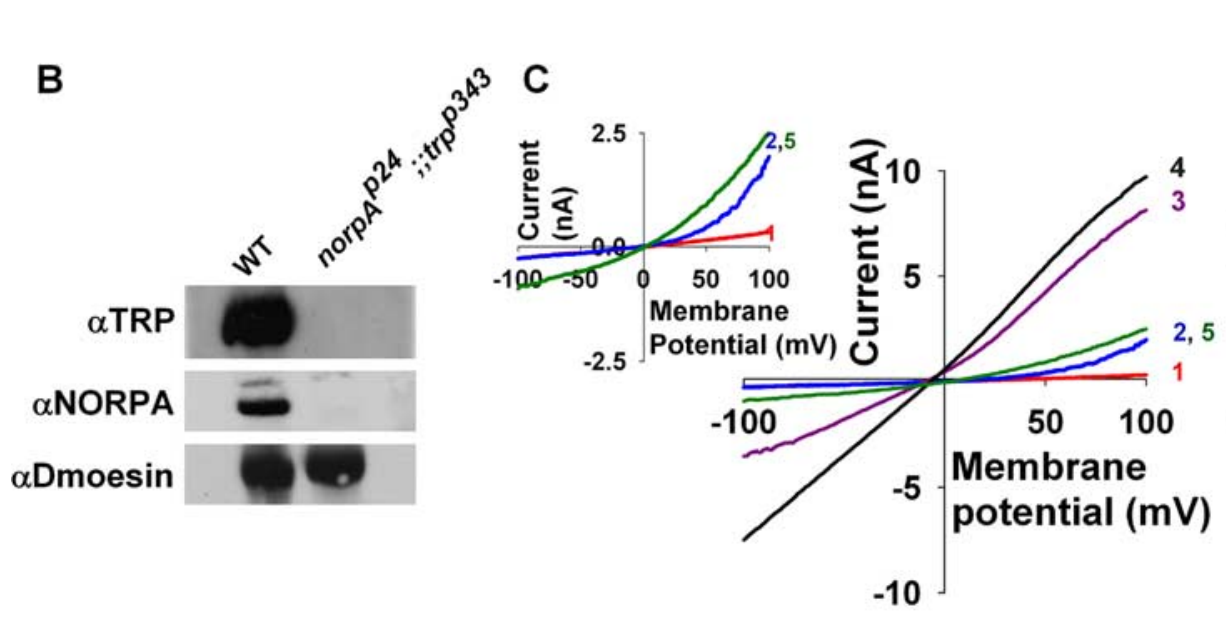

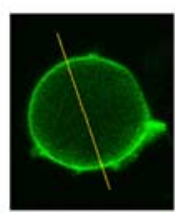
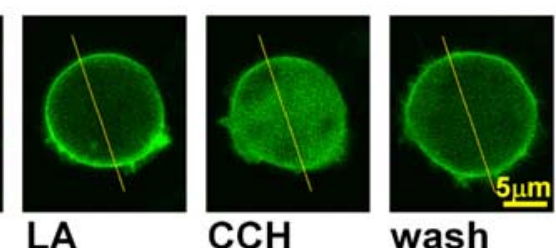

control LA
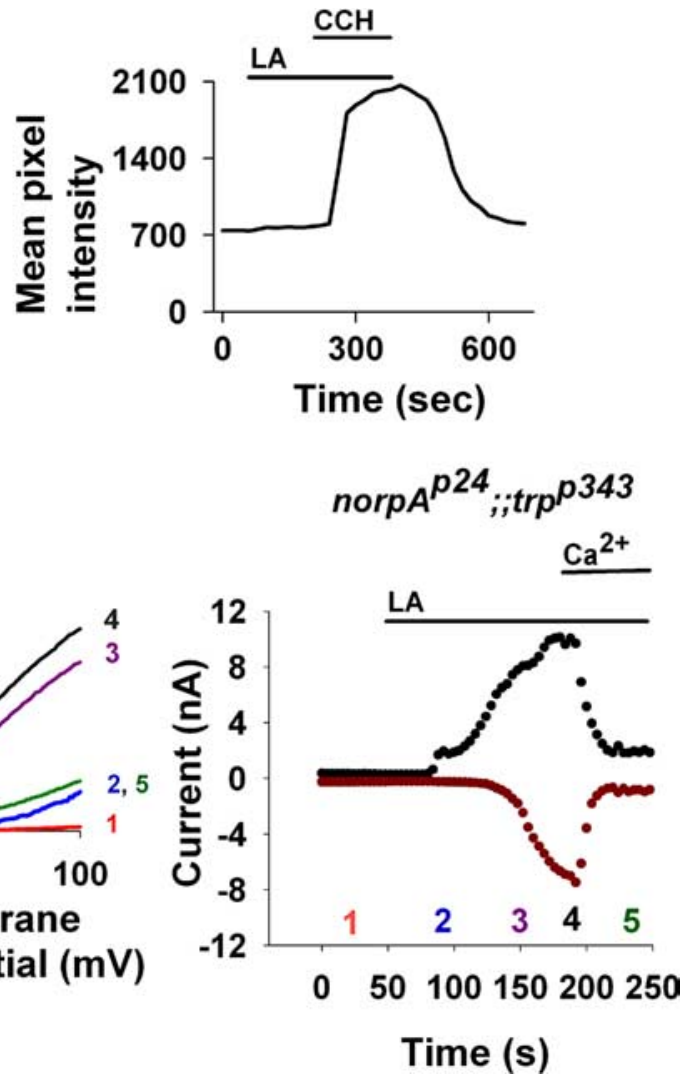

Figure 2. The action of LA is not mediated via PLC. A, PLC activity was monitored by using $S 2$ cells expressing the Drosophila muscarinic receptor (DM1) and eGFP-PH, which binds to PIP and IP ${ }_{3}$. Application of $50 \mu \mathrm{m} L A$, under conditions which activated the channels, did not elicit any change in the eGFP-PH distribution, as monitored by confocal images of the GFP fluorescence (LA) relative to control. Application of carbachol (CCH) elicited a robust translocation of eGFP-PH to the cytosol, which was reversed by CCH removal (wash), thus indicating activation of PLC ( $n=6)$. The relative fluorescence intensity at a cross section of the cell (marked by line) is also presented below the confocal images. The time course of the fluorescence changes measured in the cytosol is presented on the right. $\boldsymbol{B}$, Western blot analysis of heads homogenate of dark raised WT and norp $A^{p 24}$;itrp ${ }^{p 343}$ double mutant flies. Head membrane was extracted with SDS buffer and subjected to Western blot analysis with antibodies specific for the Drosophila proteins TRP, NORPA, and Dmoesin as indicated. No TRP and NORPA proteins were detected in the norp $A^{p 24}$;itrp $p^{p 343}$ double mutant. C, Left, Representative I-V curves measured by whole-cell recordings from photoreceptors of the norp $A^{p 24}$;itrp ${ }^{p 343}$ mutant lacking PLC and the TRP channel (see $B$ ). In darkness the TRPL channels are closed (red curve 1). The effect of the $60 \mu \mathrm{m} L A$ was not altered by the absence of PLC, and a linear I-V curve was obtained (black curve 4). The effect of $L A$ at positive membrane potentials preceded that of negative membrane potentials (curves 2 and 3 , blue and purple respectively) in a similar manner to the results of Figure $1 B$ and supplemental Figure $S 2$, available at www.jneurosci.org as

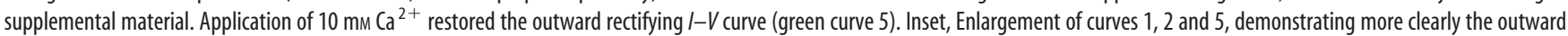
rectification. Right, The effect of $L A$ on the current is presented at $90 \mathrm{mV}$ (black dots) and $-90 \mathrm{mV}$ (dark red dots) as a function of time. The numbers correspond to the curves presented in $C$, left $(n=4)$.

express only the TRPL and TRP channels, respectively (Scott et al., 1997). We had to modify our experimental protocol to accommodate the physiological properties of the native channels. Because the rising phase of the light response to medium light intensity is very fast ( $<100 \mathrm{~ms}$ ) (Fig. 3C) (Peretz et al., 1994), voltage ramps could not be used to measure $I-V$ curves. Therefore, the following protocol was applied: The membrane potential of the photoreceptor cells was held at $-80 \mathrm{mV}$ and a constant light pulse was applied, which elicited an inward current through TRPL (Fig. 3C) and TRP (supplemental Fig. S2B,C, available at www.jneurosci.org as supplemental material) channels. Then, at various time points during the rise time of the light induced current, the membrane voltage was stepped to $80 \mathrm{mV}$ and two current values at -80 and $80 \mathrm{mV}$ were measured (Fig. 3C; supplemental Fig. S2B, $C$, available at www.jneurosci.org as supplemental material). The traces presented in Figure 3, $C$ and $D$, shows examples of early and late time points of the TRPL current. The current ratio $\left(I_{80 \mathrm{mV}} / I_{-80 \mathrm{mV}}\right)$ at the early time point was 5.01, whereas at the late time point the current ratio was reduced to 2.12, showing a reduction in the outward rectification (Fig. 3C). These experiments are summarized in Figure 3, $D$ and $E$, and supplemental Figure S2, $B$ and $C$ (available at www.jneurosci.org as supplemental material), which plot the current ratio as a function of time during the LIC. These results show that light activation of the native TRPL and TRP channels reduces the outward rectification of these channels during the rise time of the light response. This suggests that light removes OCB from these channels in timescale of $<50 \mathrm{~ms}$ and hence allows the production of a robust LIC in the presence of divalent cations (Fig. 1; supplemental Fig. S2A, available at www.jneurosci.org as supplemental material).

The results of Figures 1-3 demonstrate that exogenous application of lipids removes divalent open channel block without depolarization from constitutively active expressed TRPL channels. The results also show that LA initially activated the native TRPL and TRP channels and then removed their OCB without depolarization, suggesting that LA has a dual role of both activation and OCB removal. The relevance of OCB removal by LA to the physiological response to light was demonstrated at two levels: (1) PLC activation removed OCB from expressed TRPL channels in a manner similar to exogenous application of lipids and (2) light also alleviated OCB of native TRP and TRPL in $<50 \mathrm{~ms}$ and allows production of robust transient currents despite the existence of OCB mechanism. Because in photoreceptor cells de- 
polarization or $\mathrm{Ca}^{2+}$ removal in the dark do not open the TRP and TRPL channels, it is clear that removal of OCB by itself is not sufficient to activate these channels. Rather, OCB removal is a necessary but not sufficient step for light activation (as for the NMDA channel). The above observations led us to examine the mechanism underlying OCB alleviation by lipids without depolarization.

\section{LA reduces the blocking efficiency of divalent cations}

In addition to linearization of the $I-V$ curve by LA, Figure $1 A$ revealed that the increase in currents was faster at positive membrane potentials than at negative ones [Fig. $1 A$ left, blue (2) and purple (3) curves]. To better illustrate this nonsymmetrical effect of LA, we present the temporal behavior of the $I-V$ curves by plotting the current values at $\pm 90 \mathrm{mV}$ as a function of time (Fig. $1 \mathrm{~A}$ right, the numbers correspond to the $I-V$ curves seen in Fig. $1 A$, left). It has been shown that depolarization reduces the blocking efficiency of divalent cations on the TRPL channel (Parnas et al., 2007). The observation that LA had a faster effect at positive than at negative membrane potentials raises the possibility that LA acts in synergism with depolarization to reduce the blocking efficiency of divalent cations. To test this notion, we examined the magnitude of OCB as a function of $\mathrm{Mg}^{2+}$ concentration. In the absence of LA, the blocking efficiency of $\mathrm{Mg}^{2+}$ is voltage dependent (Fig. $4 A$ ). In the presence of LA, at negative membrane potentials, a significantly higher concentration of $\mathrm{Mg}^{2+}$ was needed to reach $50 \%$ inhibition, whereas the blocking efficiency of $\mathrm{Mg}^{2+}$ became voltage independent (Fig. $4 B$ ).

Thus, Figure 4 shows that LA reduced the blocking efficiency of divalent cations in a similar manner to that of positive membrane potentials. The reduced blocking efficiency of divalent cations, especially at negative membrane potential, abolishes the outward rectification of the TRPL channels until a linear $I-V$ curve is obtained. This occurs despite the presence of divalent cations.

LA increases cations passage rate through the channel pore Because LA reduces the blocking efficiency of divalent cations, we examined whether LA exerts this effect on the channel pore where the block occurs (Chung et al., 2005). To this end, we performed single-channel recordings of TRPL expressed in S2 cells. We first demonstrated that linearization of the $I-V$ curve by LA is also observed in single-channel measurements. Inside-out patchclamp recordings ( $4 \mathrm{~mm} \mathrm{Mg}^{2+}$ ) showed that before LA application there is a higher open probability at positive membrane po-
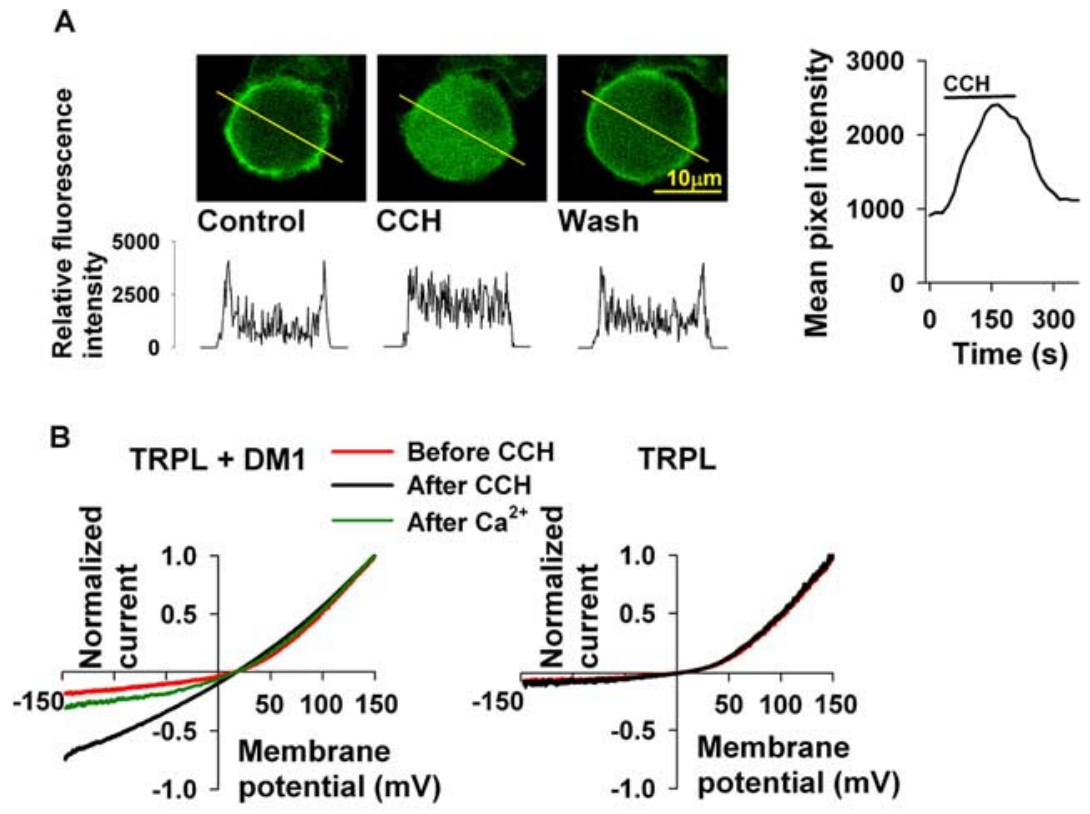

C

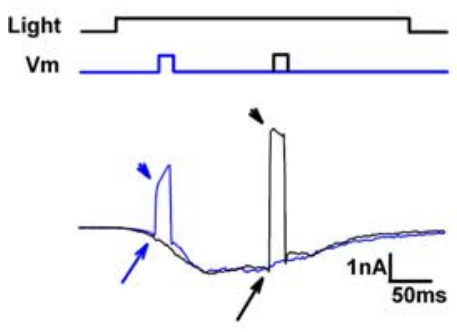

Figure 3. A reduction of $O C B$ by activation of PLC. $A, B$, Activation of the DM1 receptor by $C C H$ activated $P L C$ and removed divalent $O C B$ in $S 2$ cells. $A$, A representative series of confocal images of $S 2$ cells coexpressing eGFP-tagged PH domain, TRPL channels, and DM1. In control conditions, the plasma membrane is strongly marked by eGFP-PH fluorescence due to its binding to $\mathrm{PIP}_{2}$ (control). The relative fluorescence intensity at a cross section of the cell (marked by line) is also presented below the confocal images. Application of $\mathrm{CCH}_{\text {to }}$ the bathing solution, in a concentration that activated the TRPL channels $(\boldsymbol{B}, 100 \mu \mathrm{M} C \mathrm{CH})$, induced movement of the eGFP-tagged PH domain to the cell body $(\mathrm{CCH})$, thus indicating the activation of PLC and hydrolysis of $\mathrm{PIP}_{2}$. Subsequent wash of $\mathrm{CCH}$ from the bathing solution resulted in reversible marking of the plasma membrane with eGFP-tagged PH domain (wash, $n=6$ ). The time course of the fluorescence changes measured in the cytosol is presented on the right. $\boldsymbol{B}$, Left, Whole-cell recordings from S2 cells as in $A$. Application of $100 \mu \mathrm{M}$ CCH to S2 cells expressing both TRPL and DM1 increased the inward currents relative to the outward current, and a nearly linear I-V curve was observed (black curve). Right, Control S2 cells expressing the TRPL channel and the eGFP-PH domain but not the DM1 receptor show no effect of carbachol $(n=6)$. $\boldsymbol{C}$, Illumination reduced the outward rectification of the native TRPL channels. Whole-cell recordings from isolated ommatidia of the $\mathrm{rp}^{p 343}$ null mutant that expresses only the TRPL channels. The membrane potential of the photoreceptor cell was held at $-80 \mathrm{mV}$ and a constant light pulse was applied, which elicited an inward current through the TRPL channels. Then, at various time points during the rise time of the $L I C$, the membrane voltage was stepped to $80 \mathrm{mV}$, and two current values at $-80 \mathrm{mV}$ and $80 \mathrm{mV}$ were measured. The traces show an example of early and late time points. $D, A$ summery of experiments as presented in $C$. The current ratio at $80 \mathrm{mV}$ and $-80 \mathrm{mV}$ was calculated and presented as a function of time from the beginning of the LIC (from the time that the LIC reached $50 \mathrm{pA}$ ). It is seen that as the LIC progressed the ratio became closer to 1, indicating a reduction in the OCB. $E, A$ histogram of the results presented in $\boldsymbol{D}$. The first bin $(0-50 \mathrm{~ms})$ significantly differs from the rest of the bins $(p<0.001, n \geq 5)$. tentials than at negative ones (Fig. 5A) (Parnas et al., 2007). After application of $10 \mu \mathrm{M} \mathrm{LA}$, a significant increase of the channels' open probability was observed, mainly at the negative membrane potentials, and the open probability was almost independent of membrane potential (Fig. $5 B, C$ ).

The effect of LA on the channel pore was examined by measuring the single-channel current. These measurements showed that LA increased the single-channel current from 5.5 to $7.1 \mathrm{pA}$ at $100 \mathrm{mV}$ membrane potential (Fig. 5D) $(p<0.001)$. For a reliable single-channel current analysis, only opening events longer than 


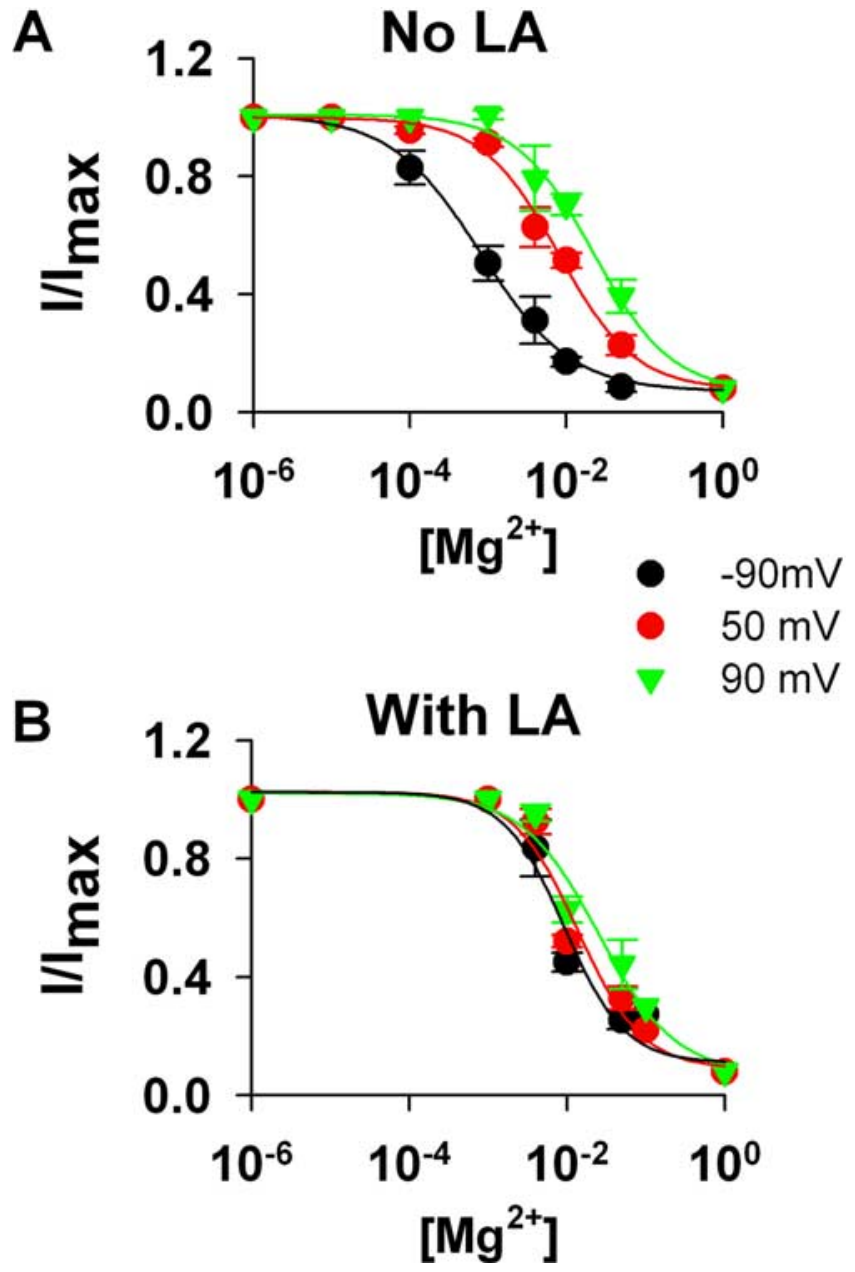

Figure 4. LA reduced the blocking efficiency of divalent cations on the TRPL channels. $\boldsymbol{A}$, Measurements of normalized whole-cell currents $\left(I / I_{\text {max }}\right)$ in response to voltage ramps, at the indicated voltages, as a function of $\mathrm{Mg}^{2+}$ concentration. The graphs present measurements at three holding potentials, $-90 \mathrm{mV}$ (black curves), $50 \mathrm{mV}$ (red curves), and $90 \mathrm{mV}$ (green curves), before application of LA. Relatively low concentrations of $\mathrm{Mg}^{2+}$ were required to block the current at negative membrane potential, compared with positive membrane potentials $(n=$ 5). $\boldsymbol{B}$, The paradigm of $\boldsymbol{A}$ was repeated after application of $L A$. Only a small difference between curves, which were measured at positive and negative membrane potentials, was observed. This indicates that $\mathrm{LA}$ removed the voltage dependence of the $\mathrm{Mg}^{2+}$ block. Accordingly, $\mathrm{EC}_{50}$ at $-90 \mathrm{mV}$ was $0.8 \pm 0.01 \mathrm{~mm}$ in the control $(\boldsymbol{A})$ and it was shifted to $9.35 \pm 2.4 \mathrm{~mm}$ after LA application. The effect of $L A$ on the $\mathrm{EC}_{50}$ value decreased with the increase in depolarization. At $50 \mathrm{mV}$, the control $\mathrm{EC}_{50}$ was $7.9 \pm 0.8 \mathrm{~mm}(\boldsymbol{A})$ and it was shifted to $13.8 \pm 3.6 \mathrm{~mm}$ after LA application $(n=5)$.

$2 T_{\mathrm{r}}$ were used (Colquhoun and Sigworth, 1995) $\left(T_{\mathrm{r}}\right.$ is the risetime of channel opening; see Materials and Methods).

The observed increase in single-channel current could arise from an increase in the permeability of the channel. To measure ionic permeability ratios, we used the procedure that was previously described (Reuss et al., 1997). Accordingly, we measured the reversal potential under bi-ionic conditions in which $\mathrm{Cs}^{+}$was the only cation included in the pipette solution. The bath contained one of a variety of monovalent cations (Fig. $5 E$, see scheme). Under these conditions, the permeability can be derived from the bi-ionic reversal potential $\left(E_{\text {rev }}\right)$. Using this approach, we examined the effect of $L A$ on $E_{\text {rev }}$ of three monovalent organic cations of increased diameters: diethylamine (DE-amine), triethylamine (TriE-amine) and tetraethylamine (TE-amine). Monovalent organic cations were used for two reasons. (1) They allow a systematic stepwise increase of the monovalent cationic diame- ter. (2) The permeability of inorganic monovalent cations is very fast and changes in their permeability might be too small to be detected. We observed the following differences among the permeabilities of the various monovalent organic cations: TE-amine did not pass through the TRPL channel and showed no inward current $\left(E_{\text {rev }}\right.$ of $\left.-48.2 \pm 3.1\right)$ (supplemental Fig. $\mathrm{S} 3 B$, available at www.jneurosci.org as supplemental material), whereas DEamine $\left(E_{\text {rev }}\right.$ of $\left.8.8 \pm 1.9\right)$ (Fig. $\left.5 E\right)$ and TriE-amine ( $E_{\text {rev }}$ of $-8.5 \pm 1.9$ ) (supplemental Fig. S3A, available at www. jneurosci.org as supplemental material) generated a small inward current. Application of LA to the extracellular solution, which contained only DE-amine resulted in a large increase of the inward currents (Fig. 5E). LA application to the TriE-amine containing solution also increased the inward currents but to a lesser extent (supplemental Fig. S3A, available at www.jneurosci.org as supplemental material). Application of LA to a TE-amine containing solution did not induce any inward current (supplemental Fig. S3B, available at www.jneurosci.org as supplemental material). Importantly, the reversal potential during application of LA did not change in any of the experiments, thus indicating that no change in TRPL permeability was induced by LA, despite the large increase in current (Fig. 5E; supplemental Fig. S3, available at www.jneurosci.org as supplemental material). In addition, the data showed that in the absence of LA, all the organic cations that were examined produced outward rectification despite the lack of divalent cations. This indicates that large monovalent organic cations also block the open channel (see below) (Fig. 5E; supplemental Fig. S3, available at www.jneurosci.org as supplemental material).

How can the effect of LA on the TRPL channels be explained, when no effect was found on the channel permeability? Hille and colleagues have previously investigated the mechanism underlying the passage of large organic cations through the $\mathrm{K}^{+}$channel pore (Sanchez et al., 1986). They found that although $\mathrm{K}^{+}$ions show a linear $I-V$ curve, organic cations, that had similar permeability to that of $\mathrm{K}^{+}$ions, revealed outwardly rectifying $I-V$ curves. In addition, they found that the single-channel current was dramatically reduced in the presence of the organic cations. These authors concluded that the organic cations blocked the open pore by a slow passage through the channel pore. According to this notion, linearization of the $I-V$ curve is expected to occur when the rate of ion passage through the channel pore is increased. To examine whether DE-amine (before application of LA) produced the outward rectification by a slow passage through the pore (Fig. $5 E$ ), we examined the permeability and single-channel current of DE-amine relative to those of $\mathrm{Na}^{+}$. Figure $5 \mathrm{~F}$ shows that $\mathrm{DE}$-amine and $\mathrm{Na}^{+}$(when $\mathrm{Cs}^{+}$was the intracellular cation) showed the same $E_{\text {rev }}$, thus indicating that they have the same permeability. However, the single-channel current was largely reduced by DE-amine (Fig. $5 G$ ). The similarity between the results of Figure 5 and the previous study of Hille and colleagues on the $\mathrm{K}^{+}$channels (Sanchez et al., 1986) suggests that the blocking effect of both large organic and divalent cations is by slow passage through the channel pore. The slow passage of the blocking cations produces only a small inward current by itself, whereas the large outward current is obtained by the small inorganic cation $\left(\mathrm{Cs}^{+}\right)$after repulsion of the blocking cation. Therefore, the effect of LA is by facilitating the passage of the blocking cation through the pore.

Further support for our notion that LA increases the rate of passage of cations through the channels was obtained by analysis of the mean open time and bursting behavior of the channel according to a kinetic model of the TRPL channel. For a detailed 
explanation see supplemental mathematical model and supplemental Fig. S4, available at www.jneurosci.org as supplemental material.

All of the above results indicated that LA facilitates the flow rate of large cations through the TRPL channel, suggesting that this is the mechanism by which LA reduces the blocking efficiency of divalent cations and alleviate OCB.

\section{Modulation of membrane properties alleviates OCB}

Diverse lipids and lipophilic compounds are known to activate or modulate the activity of TRP (Chyb et al., 1999; Hu et al., 2006) and other channels (Casado and Ascher, 1998; Patel et al., 2001; Lundbaek et al., 2005). This raises the possibility that lipids do not affect the TRPL channel by direct and/or specific binding, but rather by affecting the properties of the plasma membrane at the channel-lipid boundary (Reaves and Wolstenholme, 2007). To examine this possibility, we used procedures that are known to affect plasma membrane properties. Hypoosmotic solutions that cause cell swelling strongly affect the interaction of channels with the surrounding lipids of the plasma membrane (Hamill, 2006; Janmey and Kinnunen, 2006; Spassova et al., 2006). We therefore examined whether hypoosmotic solutions change the $I-V$ curve. Two hypoosmotic solutions of 290 and $255 \mathrm{mOsm}$ were used. Concomitantly with the increase in surface area (Fig. 6A), the inward current was reversibly enhanced and a more linear $I-V$ curve was observed (Fig. 6B) (for a statistical analysis and control, see supplemental Fig. S5A, available at www.jneurosci. org as supplemental material).

An additional method to affect the membrane properties and hence the TRPL-membrane lipid boundary is to reduce the concentration of $\mathrm{PIP}_{2}$ in the inner leaflet of the plasma membrane (Janmey and Kinnunen, 2006). Application of polylysine is known to sequester $\mathrm{PIP}_{2}$ from the membrane and to affect the activity of mammalian TRP channels (Stein et al., 2006). Exposing the intracellular membrane to polylysine linearized the $I-V$ curve of the TRPL channel (Fig. 6C), which was reversed into outward rectification by application of $5 \mathrm{~mm} \mathrm{Ca}{ }^{2+}$. Furthermore, application of polylysine in excised inside-out patch-clamp experiments greatly increased the open probability of the TRPL channel (Fig. 6D, top). This increase was accompanied by an increase in single-channel current at $100 \mathrm{mV}$ membrane potential (from 5 to $7.1 \mathrm{pA}, p<0.001$ ), similar to that observed for application of LA (compare Figs. $5 D$ and $6 D$, bottom). This

\section{With divalent}

A
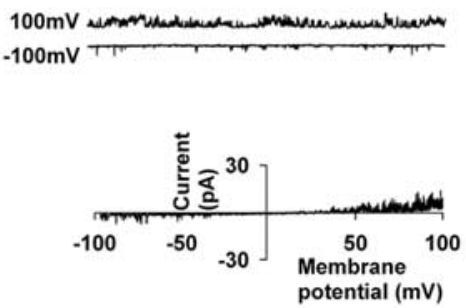

C

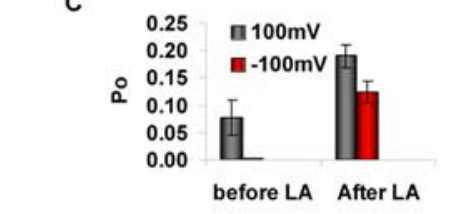

B
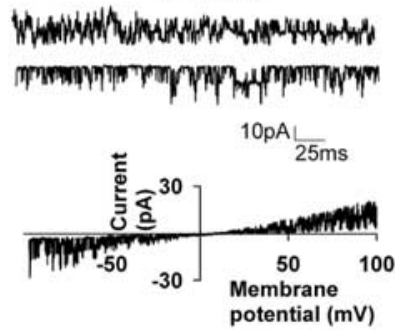
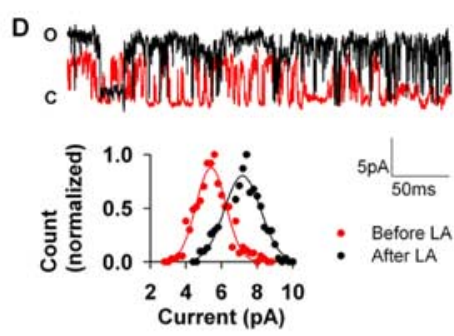

Divalent Free
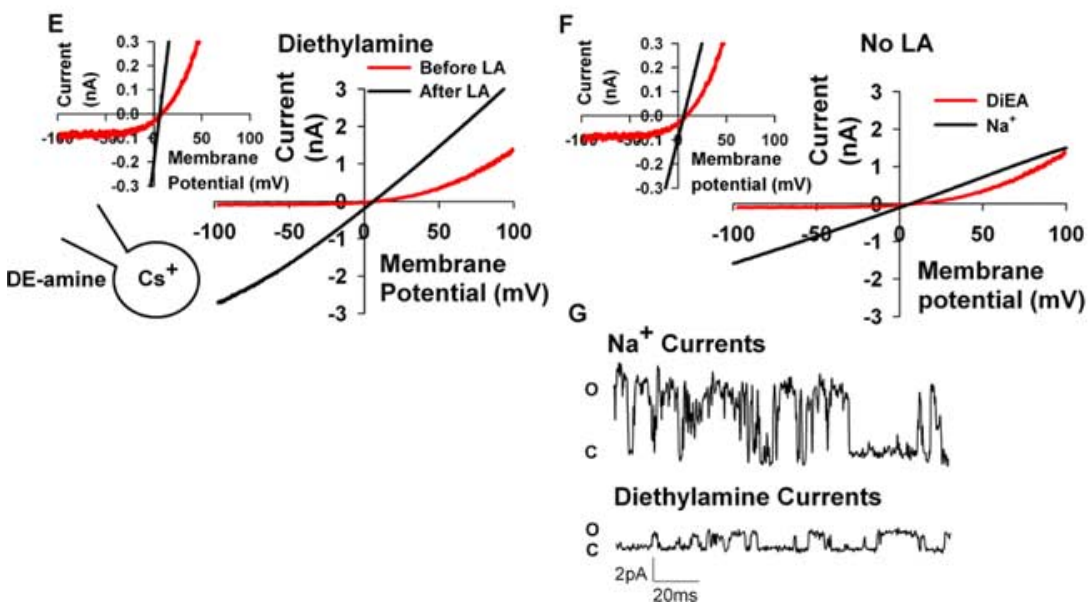

Figure 5. LA increased the passage rate of cations through the channel pore. $\boldsymbol{A}$, Inside-out patch-clamp recording from $\mathbf{S 2}$ cells expressing TRPL in symmetrical $\mathrm{Na}^{+}$solution (see Materials and Methods). Representative single-channel recordings at $\pm 100 \mathrm{mV}$ membrane potentials (top) and a representative voltage ramp from -100 to $100 \mathrm{mV}$ (bottom) are shown $(n=5)$. $\boldsymbol{B}$, The paradigm of $\boldsymbol{A}$ was repeated after application of $10 \mu \mathrm{m} L A$ (data recorded from the same cell as in $A$ ). An increase in channel activity was observed especially at negative membrane potentials $(n=5)$. C, Histogram showing the apparent open probability of the TRPL channel which was calculated from the step traces of $\boldsymbol{A}$ and $\boldsymbol{B}$. At $-100 \mathrm{mV}$ membrane potential, the measured open probability was 0.004 , whereas at 100 $\mathrm{mV}$ membrane potential, the measured open probability was 0.1 (i.e., a 25 -fold larger at positive membrane voltage). After application of $10 \mu \mathrm{m} \mathrm{LA}$, the measured open probability increased to 0.11 and 0.17 at negative and positive membrane voltages, respectively. Thus, at $100 \mathrm{mV}$ there was only a 1.5 -fold increase in the open probability in the presence of $L A(n=5)$. $\boldsymbol{D}, \mathrm{LA}$ increased the unitary channel conductance. Top, Inside-out patch-clamp recordings in standard bath solution at $100 \mathrm{mV}$ holding potential revealed TRPL channel activity before (red trace) and after (black trace) application of $10 \mu \mathrm{m}$ LA. Bottom, Amplitude histogram of the channel openings before (red dots) and after (black dots) LA application. The measurements showed that LA increased the single-channel current from $5.5 \mathrm{pA} \mathrm{to} 7.1 \mathrm{pA}$ ( $p<$ $0.001, n=7$ ). $\boldsymbol{E}$, Whole-cell recordings from S2 cells expressing the TRPL channel under bi-ionic conditions (the extracellular solution contained DE-amine (a large monovalent organic cation), whereas the intracellular solution contained Cs ${ }^{+}$(see scheme). The experiment was performed under divalent free conditions. I-V curve measurements before and after application of $40 \mu \mathrm{m} L A$ are presented. No change in $E_{\text {rev }}$ was observed. Inset, The $I-V$ curve of $\boldsymbol{E}$ is presented in a magnified current $s c a l e(n=6) . \boldsymbol{F}, I-V$ curves were measured by whole-cell recordings from S2 cells expressing the TRPL channel under bi-ionic conditions with either DE-amine or $\mathrm{Na}^{+}$as the extracellular cation $\left(\mathrm{Cs}^{+}\right.$was the intracellular cation, i.e., in divalent free conditions). No change in $E_{\text {rev }}$ between the two conditions was observed. Inset, The $I-V$ curve of $\boldsymbol{F}$ is presented in a magnified current scale $(n \geq 6)$. $\boldsymbol{G}$, Single-channel recordings from excised inside-out patch-clamp measurement at $100 \mathrm{mV}$ membrane potential when $\mathrm{Na}^{+}(130 \mathrm{~mm})$ was the sole ion (top). When $\mathrm{Na}^{+}$was replaced by DE-amine (130 $\mathrm{mm}$ ) the single-channel current was largely reduced (bottom) $(n=4)$.

result suggests that both LA and polylysine exert a similar effect on the TRPL channel.

Another approach to test the above notion is to block the effect of lipids with a venom toxin. The tarantula peptide 
A

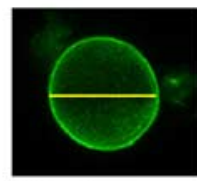
$330 \mathrm{mOsm}$

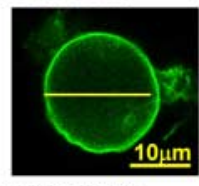
$255 \mathrm{mOsm}$ C polylysine D

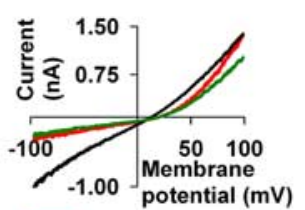

Os polylysine

- 95s polylysine

- application of $\mathrm{Ca}^{2+}$
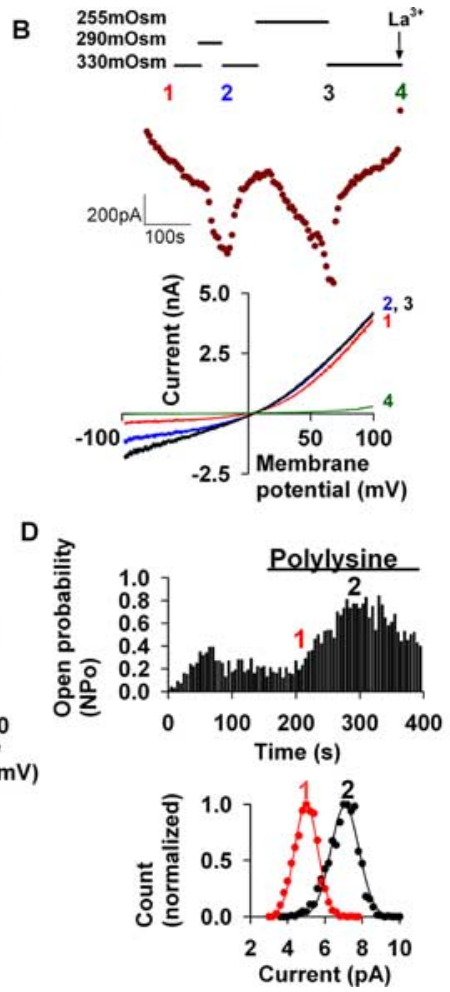

\section{E}
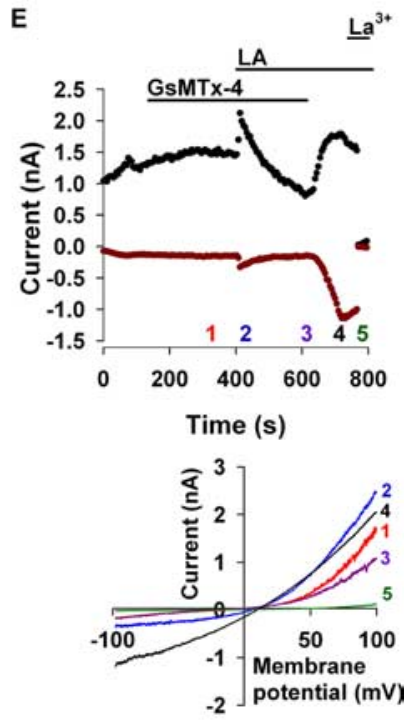

LA removes OCB from heterologously expressed and native post synaptic NMDA channels of hippocampal brain slices

The ionotropic glycine and glutamate activated NMDA channel plays a key role in the induction of many forms of synaptic plasticity (Kandel, 2000). The NMDA channel is a classical model for a channel that undergoes OCB by $\mathrm{Mg}^{2+}$, which is alleviated by depolarization (Mayer et al., 1984). However, unlike TRPL, the NMDA channel is not activated by LA in the absence of agonist (data not shown). Therefore, it was interesting to examine whether LA also alleviate the OCB of NMDA channels. In addition, it is well known that NMDA channel activation by ligand binding and OCB removal by depolarization are two distinct processes (Kandel, 2000). Therefore, the use of the NMDA channel further allows the isolation of the effect of LA on OCB from channel activation.

S2 cells, expressing the two subunits of the NMDA channel, NR1 and NR2B (Sucher et al., 1996), were activated by NMDA and glycine. In the presence of 4 mM external $\mathrm{Mg}^{2+}$, an outwardly rectifying $I-V$ curve was observed (Fig. 7A, left, red curve 1). Similar to the TRPL channel, addition of $40 \mu \mathrm{M}$ LA enhanced first the outward current (Fig. 7A, left, blue curve 2 ) and then the inward current, reaching close to a linear $I-V$ curve (Fig. $7 \mathrm{~A}$, left, black curve 3). To better illustrate the nonsymmetrical effect of LA on the NMDA channel, we present the temporal behavior of the $I-V$ curves at $\pm 90 \mathrm{mV}$, and results similar to those found for the TRPL channel were observed (Fig. 7A, right). Increasing the external $\mathrm{Mg}^{2+}$ to $50 \mathrm{~mm}$ blocked the inward current (Fig. 7A, left, green curve 4; for statistical analysis, see supplemental material and supplemental Fig. $\mathrm{S} 5 \mathrm{C}$, available at www.jneurosci.org as GsMTx-4 specifically blocks a range of stretch-activated channels, but not by specific interaction with the channel proteins themselves but rather by modification of the channel-lipid boundary (Suchyna et al., 2004; Hamill, 2006; Spassova et al., 2006). Figure 6 E shows that the GsMTx- 4 toxin did not block the constitutive activity of the expressed TRPL channel. However, in the presence of the toxin, the effect of LA was small and rapidly blocked. Washout of the toxin revealed the full extent of the effect of LA on the TRPL channel (for statistical analysis, see supplemental material and Fig. S5B, available at www.jneurosci.org as supplemental material). This result further supports the notion that LA affects the TRPL-membrane lipid boundary.

Although the results of each experiment (Fig. 6) can lead to several possible interpretations (Spassova et al., 2006; Mederos y Schnitzler et al., 2008), the ensemble of all experiments is in favor of a mechanism operating by modulating the plasma membrane properties. supplemental material). In addition, no change in $E_{\text {rev }}$ was observed (Fig. 7A) as was also true for TRPL channel. For the NMDA channel, it was shown that at positive membrane potentials there is no $\mathrm{Mg}^{2+}$ block (Perouansky and Yaari, 1993). Yet Figure 7A shows that LA causes an increase of current at positive membrane potentials. This result is in agreement with previous studies, showing potentiation of the currents that are mediated by expressed NMDA channels after application of lipids, although the underlying mechanism is still unknown (Miller et al., 1992; Kloda et al., 2007). However, the linearization of the $I-V$ curve (Fig. $7 A$ ) indicates, that in addition to the observed potentiation there is also removal of the $\mathrm{Mg}^{2+}$ OCB. In addition, we performed single-channel analysis of the NMDA channel. Similar to TRPL channels, application of LA $(10 \mu \mathrm{M})$ increased the single-channel current from 11 to $13 \mathrm{pA}$ at $100 \mathrm{mV}$ membrane potential $(p<0.001)$ (Fig. $7 B)$. In addition, LA enhanced the open probability of the single-channel activity (Fig. $7 C$ ).

To further examine the effect of LA on removal of OCB from 
NMDA channels under physiological conditions, we examined NMDA channel mediated currents that were elicited by afferent stimulation in hippocampal brain slices. To this end, whole-cell recordings from CA1 pyramidal cells of rat brain slices were conducted. Electrical stimulations of the Schaffer collateral afferent neurons elicited pharmacologically isolated NMDA channels-mediated EPSCs in the CA1 pyramidal cells (see Materials and Methods) (Crépel et al., 1997). Figure 8A shows a series of NMDA channel mediated EPSCs at various membrane potentials in the presence of $1.2 \mathrm{mM}$ extracellular $\mathrm{Mg}^{2+}$ ions, which blocked the EPSCs only at negative membrane potential (Fig. $8 \mathrm{~A}$, left). Strikingly, repeating the protocol of the control (Fig. $8 \mathrm{~A}$, left) in the presence of LA in the recording pipette induced a significant increase in the EPSCs at negative membrane potentials, despite the presence of the blocking $\mathrm{Mg}^{2+}$ ions (Fig. $8 A$, right). Figure $8 B$ summarizes the data of experiments similar to that of Figure $8 \mathrm{~A}$. The absolute values of the EPSCs' peak without (control) and with LA are plotted as a function of membrane potential. In the control experiments, a typical voltage dependent $I-V$ curve of native NMDA channels was observed (Crépel et al., 1997), with little change up to $-40 \mathrm{mV}$ and with a full removal of $\mathrm{Mg}^{2+}$ OCB at $-20 \mathrm{mV}$ membrane potential and above, as manifested by a linear $I-V$ curve. Importantly, in the presence of LA in the pipette, the negative slope of the $I-V$ curve was significantly shifted to a more negative membrane potential. Furthermore, a significant increase of the inward current already at $-50 \mathrm{mV}$ was observed, with a full removal of $\mathrm{Mg}^{2+} \mathrm{OCB}$ already at $-30 \mathrm{mV}$ membrane potential and above (Fig. $8 B$ ). In contrast to the expressed NMDA channels (Fig. 7A), there was no increase (relative to control) in the absolute currents at positive membrane potentials after application of LA. This result indicates that LA had no significant effect after a full removal of $\mathrm{Mg}^{2+} \mathrm{OCB}$, thus ruling out potentiation of NMDA channel currents by LA under physiological conditions.

Together, the results demonstrate a remarkable commonality between the TRPL and NMDA channels: both revealed removal of divalent OCB by lipids without depolarization.

\section{Discussion}

We have shown here a novel mechanism of OCB alleviation. The data suggest that OCB removal by LA arises from an increased flow rate of the blocking divalent cations through the channel pore. Modulation of the channel-membrane lipid interface might underlie the increase in the flow rate of the blocking cations and the removal of the OCB. We applied various methods to modify membrane lipid properties of the TRPL channel including: stretch of the plasma membrane by hypoosmotic solutions, sequestration of $\mathrm{PIP}_{2}$ by polylysine and application of GsMTx-4

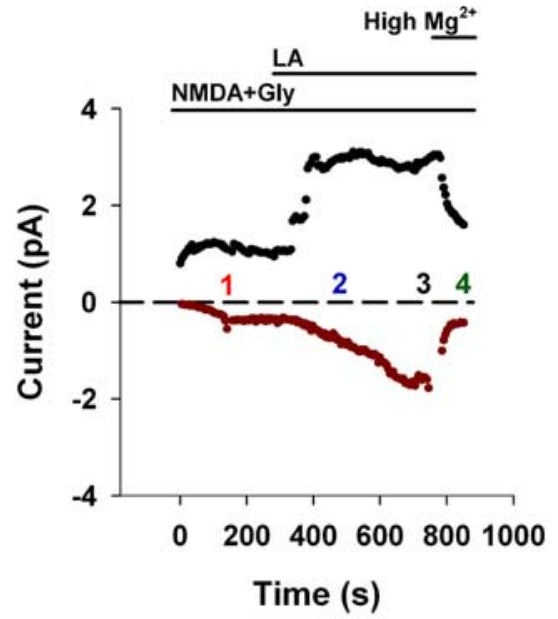

C

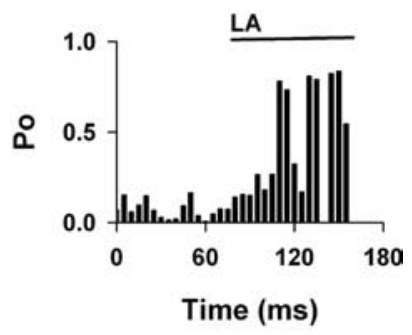

Figure 7. LA removed $\mathrm{Mg}^{2+} O C B$ from the NMDA channel. $\boldsymbol{A}$, Left, LA affected the NMDA channel in a similar manner to its effect on the TRPL channel. Whole-cell recordings from S2 cells expressing the two subunits of the NMDA channel, NR1 and NR2B. The channel was activated by combined application of NMDA (30 $\mu \mathrm{m})$ and glycine (30 $\mu \mathrm{M})$ (red curve 1). Application of $40 \mu \mathrm{m} L A$ membrane potentials preceded its effect at negative membrane potentials (blue curve 2). Application of $50 \mathrm{~mm} \mathrm{Mg}^{2+}$ restored the outward rectifying $I-V$ curve (green curve 4). Right, The effect of $L A$ is presented as a function of time, by presenting the 4). $\boldsymbol{B}$, Top, Single-channel activity of the NMDA channel before (red trace) and after (black trace) application of $10 \mu m$ LA. Traces obtained from inside-out patch-clamp recordings using standard bath solution at $100 \mathrm{mV}$ holding potential. Bottom, Amplitude the single-channel current from 11 to $13 \mathrm{pA}(p<0.001, n=3)$. C, Inside-out patch-clamp recordings from $S 2$ cells expressing the NMDA channel showed an increase in the open probability of the channels after application of $10 \mu \mathrm{m} L A(n=3)$.

toxin and various lipids such as LA, OA and SAG. Although the results of each of these experiments can lead to several possible interpretations, the ensemble of all experiments is in favor of a mechanism operating by modulation of the plasma membrane properties, which affect channel-membrane lipid interactions. The results thus suggest that lipids do not affect the TRPL channel as second messengers but rather as modifiers of membrane lipidchannel interactions.

The TRPL and NMDA channels revealed striking similarity in the mechanism underlying their $\mathrm{OCB}$ and its removal. Both channels undergo OCB by divalent cations, which was removed by depolarization (Mayer et al., 1984; Parnas et al., 2007), and they were similarly affected by lipids. Accordingly, LA caused linearization of the $I-V$ curve; the outwardly rectifying $I-V$ curve could be restored on increasing the concentration of the divalent cations; LA increased the single-channel current, and no change in $E_{\text {rev }}$ was observed after application of LA. Together, these results suggest that a common mechanism underlies OCB removal by lipids from the TRPL and NMDA channels. For the NMDA 
A

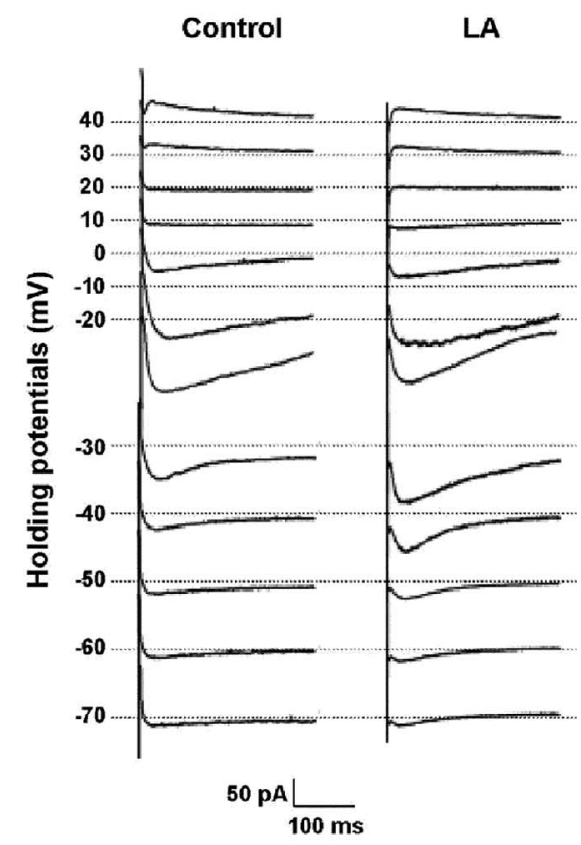

B

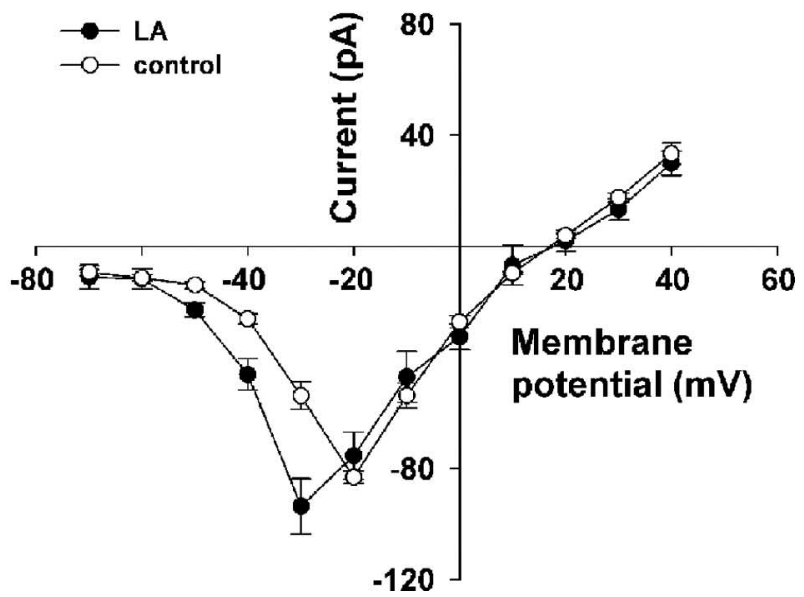

Figure 8. LA removed $\mathrm{Mg}^{2+} \mathrm{OCB}$ from the native NMDA channel in hippocampal CA1 pyramidal neurons. $\boldsymbol{A}$, Representative NMDA channel mediated EPSCs recorded at different holding potentials in the absence (control) and presence (in the pipette) of $30 \mu \mathrm{M} L \mathrm{~A}(\mathrm{LA})$ and in the presence of $100 \mu \mathrm{m}$ picrotoxin and $10 \mu \mathrm{M}$ CNQX in the extracellular solution. EPSCs were evoked orthodromically and recorded in a CA1 pyramidal cell layer using whole-cell voltage clamp. $\boldsymbol{B}, \mathrm{A}$ plot of the EPSCs' peak amplitudes (not normalized) vs membrane potentials for the control (empty circles, $n=5$ ) and LA (filled circles, $n=7$ ). Error bars are SEM.

channel, activation by ligands and removal of OCB are two distinct processes (Kandel, 2000). However, this is not the case for the TRPL channel, in which activation of PLC underlies both channel activation and removal of OCB. In the heterologously expressed TRPL, the channels are already in their active state and the negligible single-channel activity at negative membrane potential (Fig. $5 A$ ) is due to OCB that can be removed by depolarization. In contrast, in the native photoreceptor cells the channels are closed in the dark and depolarization cannot open the channels (Fig. $1 B$, red). PLC activation by light or application of PUFAs is required to activate the native channels. However, divalent $\mathrm{OCB}$ is an efficient and fast process, which is expected to quickly block the activated channels and prevent current flow through the channel pore. Therefore, we suggest that activation of PLC (or application of PUFA) has a dual role: to activate the channel by a still unknown mechanism (Leung et al., 2008) and to remove OCB. The facts that expressed TRPL channels in the presence of divalent cations are not active at negative membrane potentials and that they can be activated by depolarization or membrane lipid modulations support the notion that activation and removal of OCB are two different processes. The present study highlights the need to remove OCB to allow current flow through the active channel. We show that PLC activation, which converts $\mathrm{PIP}_{2}$ (with a large hydrophilic head-group) into DAG [with a small hydrophilic head-group (Janmey and Kinnunen, 2006)] removes OCB and allows light induced current flow through the channels in the presence of $\sim 1.5 \mathrm{~mm}$ external $\mathrm{Ca}^{2+}$ and $\sim 4 \mathrm{~mm}$ external and internal $\mathrm{Mg}^{2+}$. Figure 3, D and E, and supplemental Figure S3, available at www.jneurosci.org as supplemental material, show that at the onset of the LIC there is a strong OCB, which is reduced with the rise of the inward current at $-80 \mathrm{mV}$. These data demonstrate alleviation of OCB by light under physiological conditions.

Calcium ions are known to have diverse regulatory roles. Because TRP channels are nonselective cation channels with a relatively large pore (Owsianik et al., 2006), it is important to regulate $\mathrm{Ca}^{2+}$ entry through these channels under physiological conditions. The mechanism of OCB by slow passage is a useful mechanism to allow entry of these regulatory divalent cations, but in a controlled manner. The putative pore regions of the TRP and TRPL channel are composed of the following amino acids: ES(T)SQSLFWASFGM(L)VG(D)LDD(VS)FE(D)LS(A)GIK [where the putative selectivity filter is underlined and the amino acids of TRP are indicated in brackets where they differ from TRPL (Owsianik et al., 2006)]. Because OCB in the TRP/TRPL channels operates by slow passage of the blocking cation, it is reasonable to assume that the negatively charged amino acids (bold characters) in the pore region are involved in the OCB.

The kinetics of OCB removal by LA and by exogenous PLC activation in the heterologous expression system is rather slow (Fig. 1, time scale of seconds). This slow kinetics is partially explained by the exogenous application of the different activators (LA and $\mathrm{CCH}$ ). In contrast, the removal of OCB in the native photoreceptor cell is fast (Fig. 3D-F, time scale of milliseconds). This fast removal of OCB can be readily explained by the highly organized signaling compartment and the vast amounts of signaling molecules (e.g., PLC), which produce large quantities of lipids in a restricted area and in the ms range (Hardie and Raghu, 2001).

The current study also has important implications on the regulation of NMDA channels under physiological conditions. Previous studies have shown that the activity of NMDA channels was potentiated by PUFAs (Miller et al., 1992; Kloda et al., 2007) and by membrane stretching (Paoletti and Ascher, 1994) through alterations in the receptor's lipid environment. However, these studies either showed a large NMDA dependent current at -70 $\mathrm{mV}$ membrane potential (Miller et al., 1992), which is not typical for the native channel, or did not present the $I-V$ curve (Paoletti and Ascher, 1994). These observations led to the conclusion that arachidonic acid or stretch only potentiated the persistent NMDA channel current by a still unknown mechanism. In contrast, we show that LA induced a significant increase in the NMDA channels-mediated EPSCs at negative membrane potentials, despite the presence of the blocking $\mathrm{Mg}^{2+}$ ions and that it lacked any effect on the current at positive membrane potentials. Thus, these results indicate that LA action on NMDA channels is by the removal of divalent OCB without depolarization. 
The well known function of the NMDA channel is to serve as the coincident detector of presynaptic and postsynaptic activity. This function is achieved through OCB removal by depolarization (Kandel, 2000). Accordingly, lipid-producing pathways that reduce OCB should modulate coincidence detection. Indeed, inhibition of phospholipase A2, which produces arachidonic acid has been shown to inhibit induction of long term potentiation (LTP) without specifying a mechanism, in CA1 hippocampal neurons (Massicotte et al., 1990). Together, the effects of lipids on OCB alleviation of different ion channels allow cross talk between channel activity of prime biological importance and lipidproducing pathways.

\section{References}

Balla T, Várnai P (2002) Visualizing cellular phosphoinositide pools with GFP-fused protein-modules. Sci STKE 2002:PL3.

Berridge MJ, Irvine RF (1989) Inositol phosphates and cell signalling. Nature 341:197-205.

Bloomquist BT, Shortridge RD, Schneuwly S, Perdew M, Montell C, Steller H, Rubin G, Pak WL (1988) Isolation of a putative phospholipase C gene of Drosophila, norpA, and its role in phototransduction. Cell 54:723-733.

Casado M, Ascher P (1998) Opposite modulation of NMDA receptors by lysophospholipids and arachidonic acid: common features with mechanosensitivity. J Physiol 513:317-330.

Chung MK, Güler AD, Caterina MJ (2005) Biphasic currents evoked by chemical or thermal activation of the heat-gated ion channel, TRPV3. J Biol Chem 280:15928-15941.

Chyb S, Raghu P, Hardie RC (1999) Polyunsaturated fatty acids activate the Drosophila light-sensitive channels TRP and TRPL. Nature 397:255-259.

Clapham DE (2003) TRP channels as cellular sensors. Nature 426:517-524.

Colquhoun D, Sigworth FJ (1995) Fitting and statistical analysis of single channel recordings. In: Single-channel recording (Neher E, Sakmann B, eds), pp 483-587. New York: Plenum.

Cook B, Bar Yaacov M, Cohen-Ben Ami H, Goldstein RE, Paroush Z, Selinger Z, Minke B (2000) Phospholipase C and termination of G-proteinmediated signalling in vivo. Nat Cell Biol 2:296-301.

Crépel V, Khazipov R, Ben-Ari Y (1997) Blocking GABA(A) inhibition reveals AMPA- and NMDA-receptor-mediated polysynaptic responses in the CA1 region of the rat hippocampus. J Neurophysiol 77:2071-2082.

Devary O, Heichal O, Blumenfeld A, Cassel D, Suss E, Barash S, Rubinstein CT, Minke B, Selinger Z (1987) Coupling of photoexcited rhodopsin to inositol phospholipid hydrolysis in fly photoreceptors. Proc Natl Acad Sci U S A 84:6939-6943.

Dhaka A, Viswanath V, Patapoutian A (2006) TRP ion channels and temperature sensation. Annu Rev Neurosci 29:135-161.

Estacion M, Sinkins WG, Schilling WP (2001) Regulation of Drosophila transient receptor potential-like (TRPL) channels by phospholipase C-dependent mechanisms. J Physiol 530:1-19.

Hamill OP (2006) Twenty odd years of stretch-sensitive channels. Pflugers Arch 453:333-351.

Hardie RC (2007) TRP channels and lipids: from Drosophila to mammalian physiology. J Physiol 578:9-24.

Hardie RC, Minke B (1994) Calcium-dependent inactivation of lightsensitive channels in Drosophila photoreceptors. J Gen Physiol 103:409-427.

Hardie RC, Mojet MH (1995) Magnesium-dependent block of the lightactivated and trp-dependent conductance in Drosophila photoreceptors. J Neurophysiol 74:2590-2599.

Hardie RC, Raghu P (2001) Visual transduction in Drosophila. Nature 413:186-193.

Hardie RC, Reuss H, Lansdell SJ, Millar NS (1997) Functional equivalence of native light-sensitive channels in the Drosophila $\operatorname{trp}^{301}$ mutant and TRPL cation channels expressed in a stably transfected Drosophila cell line. Cell Calcium 21:431-440.

Hardie RC, Martin F, Chyb S, Raghu P (2003) Rescue of light responses in the Drosophila "null" phospholipase C mutant, norpAP24 by diacylglycerol kinase mutant, rdgA and by metabolic inhibition. J Biol Chem 278:18851-18858.

Hille B (1992) Ion channels of excitable membranes. Sunderland, MA: Sinauer Associates.

Hofmann T, Obukhov AG, Schaefer M, Harteneck C, Gudermann T, Schultz
G (1999) Direct activation of human TRPC6 and TRPC3 channels by diacylglycerol. Nature 397:259-263.

Hu HZ, Xiao R, Wang C, Gao N, Colton CK, Wood JD, Zhu MX (2006) Potentiation of TRPV 3 channel function by unsaturated fatty acids. J Cell Physiol 208:201-212.

Janmey PA, Kinnunen PK (2006) Biophysical properties of lipids and dynamic membranes. Trends Cell Biol 16:538-546.

Jordt SE, McKemy DD, Julius D (2003) Lessons from peppers and peppermint: the molecular logic of thermosensation. Curr Opin Neurobiol 13:487-492.

Kandel ER (2000) Synaptic integration. In: Principles of neural science, Ch 12 (Kandel ER, Schwartz JH, Jessell TM, eds), pp 212-214. New York: McGraw-Hill, Health Professions Division.

Kaupp UB, Seifert R (2002) Cyclic nucleotide-gated ion channels. Physiol Rev 82:769-824.

Kloda A, Lua L, Hall R, Adams DJ, Martinac B (2007) Liposome reconstitution and modulation of recombinant $N$-methyl-D-aspartate receptor channels by membrane stretch. Proc Natl Acad Sci U S A 104:1540-1545.

Leung HT, Tseng-Crank J, Kim E, Mahapatra C, Shino S, Zhou Y, An L, Doerge RW, Pak WL (2008) DAG lipase activity is necessary for TRP channel regulation in Drosophila photoreceptors. Neuron 58:884-896.

Lucas P, Ukhanov K, Leinders-Zufall T, Zufall F (2003) A diacylglycerolgated cation channel in vomeronasal neuron dendrites is impaired in TRPC2 mutant mice: mechanism of pheromone transduction. Neuron 40:551-561.

Lundbaek JA, Birn P, Tape SE, Toombes GE, Søgaard R, Koeppe RE 2nd, Gruner SM, Hansen AJ, Andersen OS (2005) Capsaicin regulates voltage-dependent sodium channels by altering lipid bilayer elasticity. Mol Pharmacol 68:680-689.

Massicotte G, Oliver MW, Lynch G, Baudry M (1990) Effect of bromophenacyl bromide, a phospholipase A2 inhibitor, on the induction and maintenance of LTP in hippocampal slices. Brain Res 537:49-53.

Mayer ML, Westbrook GL, Guthrie PB (1984) Voltage-dependent block by $\mathrm{Mg}^{2+}$ of NMDA responses in spinal cord neurones. Nature 309:261-263.

Miller B, Sarantis M, Traynelis SF, Attwell D (1992) Potentiation of NMDA receptor currents by arachidonic acid. Nature 355:722-725.

Minke B, Cook B (2002) TRP channel proteins and signal transduction. Physiol Rev 82:429-472.

Minke B, Parnas M (2006) Insights on TRP channels from in vivo studies in Drosophila. Annu Rev Physiol 68:649-684.

Montell C (2005) The TRP superfamily of cation channels. Sci STKE 2005:re3.

Nadler MJ, Hermosura MC, Inabe K, Perraud AL, Zhu Q, Stokes AJ, Kurosaki T, Kinet JP, Penner R, Scharenberg AM, Fleig A (2001) LTRPC7 is a Mg.ATP-regulated divalent cation channel required for cell viability. Nature 411:590-595.

Nowak L, Bregestovski P, Ascher P, Herbet A, Prochiantz A (1984) Magnesium gates glutamate-activated channels in mouse central neurones. $\mathrm{Na}$ ture 307:462-465.

Okada T, Inoue R, Yamazaki K, Maeda A, Kurosaki T, Yamakuni T, Tanaka I, Shimizu S, Ikenaka K, Imoto K, Mori Y (1999) Molecular and functional characterization of a novel mouse transient receptor potential protein homologue TRP7. $\mathrm{Ca}^{2+}$-permeable cation channel that is constitutively activated and enhanced by stimulation of $\mathrm{G}$ protein-coupled receptor. J Biol Chem 274:27359-27370.

Owsianik G, Talavera K, Voets T, Nilius B (2006) Permeation and selectivity of TRP channels. Annu Rev Physiol 68:685-717.

Paoletti P, Ascher P (1994) Mechanosensitivity of NMDA receptors in cultured mouse central neurons. Neuron 13:645-655.

Parnas M, Katz B, Minke B (2007) Open channel block by $\mathrm{Ca}^{2+}$ underlies the voltage dependence of Drosophila TRPL channel. J Gen Physiol 129:17-28.

Patel AJ, Lazdunski M, Honoré E (2001) Lipid and mechano-gated 2P domain $\mathrm{K}(+)$ channels. Curr Opin Cell Biol 13:422-428.

Peretz A, Suss-Toby E, Rom-Glas A, Arnon A, Payne R, Minke B (1994) The light response of Drosophila photoreceptors is accompanied by an increase in cellular calcium: effects of specific mutations. Neuron 12:1257-1267.

Perouansky M, Yaari Y (1993) Kinetic properties of NMDA receptormediated synaptic currents in rat hippocampal pyramidal cells versus interneurones. J Physiol 465:223-244.

Raghu P, Usher K, Jonas S, Chyb S, Polyanovsky A, Hardie RC (2000) Con- 
stitutive activity of the light-sensitive channels TRP and TRPL in the Drosophila diacylglycerol kinase mutant, $r d g A$. Neuron 26:169-179.

Reaves BJ, Wolstenholme AJ (2007) The TRP channel superfamily: insights into how structure, protein-lipid interactions and localization influence function. Biochem Soc Trans 35:77-80.

Reuss H, Mojet MH, Chyb S, Hardie RC (1997) In vivo analysis of the Drosophila light-sensitive channels, TRP and TRPL. Neuron 19:1249-1259.

Sanchez JA, Dani JA, Siemen D, Hille B (1986) Slow permeation of organic cations in acetylcholine receptor channels. J Gen Physiol 87:985-1001.

Mederos y Schnitzler M, Storch U, Meibers S, Nurwakagari P, Breit A, Essin K, Gollasch M, Gudermann T (2008) Gq-coupled receptors as mechanosensors mediating myogenic vasoconstriction. EMBO J 27:3092-3103.

Scott K, Sun Y, Beckingham K, Zuker CS (1997) Calmodulin regulation of Drosophila light-activated channels and receptor function mediates termination of the light response in vivo. Cell 91:375-383.

Spassova MA, Hewavitharana T, Xu W, Soboloff J, Gill DL (2006) A common mechanism underlies stretch activation and receptor activation of TRPC6 channels. Proc Natl Acad Sci U S A 103:16586-16591.
Stein AT, Ufret-Vincenty CA, Hua L, Santana LF, Gordon SE (2006) Phosphoinositide 3-kinase binds to TRPV1 and mediates NGF-stimulated TRPV1 trafficking to the plasma membrane. J Gen Physiol 128:509-522.

Sucher NJ, Awobuluyi M, Choi YB, Lipton SA (1996) NMDA receptors: from genes to channels. Trends Pharmacol Sci 17:348-355.

Suchyna TM, Tape SE, Koeppe RE 2nd, Andersen OS, Sachs F, Gottlieb PA (2004) Bilayer-dependent inhibition of mechanosensitive channels by neuroactive peptide enantiomers. Nature 430:235-240.

Suh BC, Inoue T, Meyer T, Hille B (2006) Rapid chemically induced changes of PtdIns(4,5)P2 gate KCNQ ion channels. Science 314:1454-1457.

Topala CN, Groenestege WT, Thébault S, van den Berg D, Nilius B, Hoenderop JG, Bindels RJ (2007) Molecular determinants of permeation through the cation channel TRPM6. Cell Calcium 41:513-523.

Voets T, Droogmans G, Wissenbach U, Janssens A, Flockerzi V, Nilius B (2004) The principle of temperature-dependent gating in cold- and heatsensitive TRP channels. Nature 430:748-754. 